\title{
Climate projections over CORDEX Africa domain using the fifth-generation Canadian Regional Climate Model (CRCM5)
}

\author{
René Laprise • Leticia Hernández-Díaz • Kossivi Tete • \\ Laxmi Sushama $\cdot$ Leo Šeparović • Andrey Martynov • \\ Katja Winger $\cdot$ Michel Valin
}

Received: 30 July 2012/ Accepted: 22 December 2012/Published online: 22 January 2013

(C) The Author(s) 2013. This article is published with open access at Springerlink.com

\begin{abstract}
Following the CORDEX experimental protocol, climate simulations and climate-change projections for Africa were made with the new fifth-generation Canadian Regional Climate Model (CRCM5). The model was driven by two Global Climate Models (GCMs), one developed by the Max-Planck-Institut für Meteorologie and the other by the Canadian Centre for Climate Modelling and Analysis, for the period 1950-2100 under the RCP4.5 emission scenario. The performance of the CRCM5 simulations for current climate is discussed first and compared also with a reanalysis-driven CRCM5 simulation. It is shown that errors in lateral boundary conditions and sea-surface temperature from the GCMs have deleterious consequences on the skill of the CRCM5 at reproducing specific regional climate features such as the West African Monsoon and the annual cycle of precipitation. For other aspects of the African climate however the regional model is able to add value compared to the simulations of the driving GCMs. Climate-change projections for periods until the end of this century are also analysed. All models project a warming throughout the twenty-first century, although the details of the climate changes differ notably between model projections, especially for precipitation changes. It is shown that
\end{abstract}

R. Laprise · L. Hernández-Díaz $(\bowtie) \cdot$ K. Tete $\cdot$ L. Sushama · L. Šeparović · A. Martynov $\cdot$ K. Winger $\cdot$ M. Valin Centre ESCER, Département des Sciences de la Terre et de l'atmosphère, Université du Québec à Montréal (UQAM), C.P. 8888, Succ. Centre-ville, Montreal, QC H3C 3P8, Canada e-mail: leticia@sca.uqam.ca

L. Sushama

Canada Research Chair in Regional Climate Modelling,

UQAM, Montreal, QC, Canada the climate changes projected by CRCM5 often differ noticeably from those of the driving GCMs.

Keywords Regional Climate Modelling - African climate · Climate change $\cdot$ CORDEX $\cdot$ CRCM5 - West African

Monsoon - Diurnal precipitation cycle $\cdot$ Annual precipitation cycle $\cdot$ Dynamical downscaling

\section{Introduction}

The simulation of the African climate is a challenge for climate models due to the complexity and the diversity of processes to be represented, especially those contributing to the West African Monsoon (WAM). The IPCC 4th Assessment Report (IPCC AR4 2007) showed not only that there was little consensus among the climate projections for Africa (see also the review by Druyan 2010), but also that the state-of-the-art models had difficulties in simulating the key elements of current climate. The tropical rainbelt was displaced equatorward in nearly all of the coupled global climate models (CGCM) simulations, and ocean temperatures were too warm by an average of $1-2{ }^{\circ} \mathrm{C}$ in the Gulf of Guinea and typically by $3{ }^{\circ} \mathrm{C}$ off the southwest coast in the region of intense upwelling. Many CGCMs misrepresented the WAM (Cook and Vizy 2006), and in some there was no WAM at all, resulting in the summer rainfall failing to move inland from the Gulf of Guinea (IPCC AR4 2007). Although a realistic and wellvalidated current climate simulation may not be sufficient to give confidence in a climate projection, climate projections of WAM from models with unrealistic reference climates are questionable.

Hence there is a need for enhancing the knowledge and understanding of the complex interactions between the 
climate components in this region of the world. Four avenues have been taken to overcome this gap: (1) observational campaigns such as AMMA (Redelsperger et al. 2006) to get in situ information about local processes (Lafore et al. 2010), (2) model intercomparison experiments such as AMMA-MIP (Hourdin et al. 2010), ALMIP (Boone et al. 2009) and WAMME (Xue et al. 2010; Druyan et al. 2010) to identify model-specific and common biases across models, (3) improving the models' representation of the physical processes taking place in the region, and (4) the development of ensembles of simulations and projections in order to reduce the impact of model-specific biases.

One of the conclusions of the AMMA-MIP (Hourdin et al. 2010) was that climate models, when forced by observed sea surface temperatures (SSTs), roughly succeed in simulating the main features of the WAM such as the African Easterly Jet (AEJ) and the latitudinal migration of the tropical rainbelt with seasons. Nevertheless, the accumulated rainfall over the Sahel varied by an order of magnitude for the multi-model simulations in AMMAMIP, the evolution of the WAM rainfall from the Guinea Coast to the Sahel was not properly simulated and no model appeared able to simulate correctly all the aspects of the WAM system. From the side of the WAM Modeling and Evaluation (WAMME) project, Xue et al. (2010) using an ensemble of 11 Global Climate Models (GCM) arrived to similar conclusions: when the SSTs are prescribed, the models reasonably simulate the WAM seasonal-mean precipitation, surface temperature distribution and averaged zonal wind, but the majority of them fail to represent the proper intensities of the AEJ as well as the Tropical Easterly Jet (TEJ), two important elements of the WAM system.

Regarding the performance of the Regional Climate Models (RCM) in West Africa, projects such as the WAMME Regional Model Intercomparison Study (Druyan et al. 2010) and the ENSEMBLES-Africa (Paeth et al. 2011) have been carried on the assessment of RCM simulations of the WAM system.

Druyan et al. (2010) compared the performance of five RCMs forced by lateral boundary conditions (LBC) from NCEP II Reanalyses and two RCMs driven with LBC from HadAM3 GCM. All of the RCMs showed excessive precipitation over much of West Africa, which the authors found consistent with similar bias in NCEP II Reanalyses and HadAM3, the two datasets used for LBC. As in the GCM simulations, several RCM simulations failed to show a well-defined seasonal-mean AEJ core. As the AEJ is a direct consequence of the surface gradient of temperature and moisture (Burpee 1972; Cook 1999; Thorncroft and Blackburn 1999; Parker et al. 2005a, b), this can be a reflection of the models difficulties in a region of strong coupling between the surface and the atmosphere (Koster et al. 2006). Finally, the discrepancies in the results of RCMs sharing the same driving boundary conditions suggest that the internal model physics and dynamics play an important role in determining the quality of the nested simulations (Druyan et al. 2010; Paeth et al. 2011). On the other hand, the authors found that many features of the GCM seasonal-mean precipitation distribution were improved by the downscaling but that each RCM individually failed to improve upon other features.

In the ENSEMBLES-Africa project (Paeth et al. 2011), nine RCMs with 50-km grid mesh were forced by the same LBC from the ERA-Interim Reanalyses for the period 1990-2007 over a domain that included West Africa. Three RCMs showed dry biases over central equatorial Africa, while three others overestimated the annual rainfall regionally by up to $50 \%$. Paeth et al. (2011) also analysed projected annual precipitation over the 2001-2050 period for the RCMs participating in the ENSEMBLES-Africa project. Different RCMs did not agree in terms of the future precipitation changes in western and tropical Africa. However, they noted that the multi-model ensemble mean generally outperforms the skill of individual models, illustrating the advantages of multi-model assessments for past and future African climate. Nested RCM have limited skill at dynamically downscaling when driving boundary conditions are not realistic, as is the case with many GCMs that suffer large systematic biases for current climate.

A recent study of Nikulin et al. (2012) using ten RCMs driven by ERA-Interim reanalyses also showed that overall the ensemble mean improves upon the individual models simulation of precipitation, mostly as a consequence of cancellation errors between the models. Furthermore, many RCMs simulated better precipitation climatology than that of the driving reanalyses; this supports the potential for added value of high-resolution RCMs by resolving smallscale processes (Di Luca et al. 2012; Feser et al. 2011).

The COordinated Regional Climate Downscaling EXperiment (CORDEX; Giorgi et al. 2009; http://wcrp. ipsl.jussieu.fr/SF_RCD_CORDEX.html; http://www.meteo. unican.es/en/projects/CORDEX), which is an initiative of the World Climate Research Programme (WCRP; http:// www.wcrp-climate.org/), aims at regional climate modelling evaluation and improvement, and provides a standardized framework in which projections made with different CGCM participating in the Coupled Model Intercomparison Project-Phase 5 (CMIP5; Taylor et al. 2009, 2012) are dynamically downscaled by RCMs over selected continent-scale domains; see Jones et al. (2011) for more details on CORDEX Climate Projection Framework. Africa was selected as the first target region, thus providing an opportunity to improve climate-change projections over Africa. The fifth-generation Canadian RCM (CRCM5; Zadra et al. 2008; Hernández-Díaz et al. 2012, 
hereinafter HD12) recently developed at the ESCER Centre has been applied within CORDEX to simulate current climate in Africa by HD12 and in North America by Martynov et al. (2012b), and for climate projection in North America by Šeparović et al. (2012).

It is in this context that the CRCM5 is here applied over the CORDEX Africa domain, for the period 1950-2100, driven by two CGCMs-one developed at the Max-PlanckInstitut für Meteorologie (MPI-ESM-LR) in Hamburg (Germany) and the other at the Canadian Centre for Climate modelling and analysis (CanESM2) in Victoria (British-Columbia, Canada), under the RCP4.5 greenhouse gases scenario; see van Vuuren et al. (2011) for information on Representative Concentration Pathways (RCP) scenarios. This is part of our contribution to CORDEXAfrica and the aim of this paper is to describe the skill of CRCM5 in simulating current climate over Africa when driven by these two GCMs and to present the climatechange projections till the end of this century.

The paper is organised as follows. The methodology, CRCM5 description and the configuration of the simulations are presented in Sect. 2. Results for current climate obtained from the two GCM-driven CRCM5 simulations, which are compared to the observations and a previous ERA-driven CRCM5 simulation, are presented in Sect. 3, along with an evaluation of the skill of the models in simulating the WAM. The climate-change projections derived from the two GCM-driven CRCM5 simulations as well as from the two GCMs themselves follow in Sect. 4. Finally a summary of the findings and conclusions are presented in Sect. 5.

\section{Methodology}

Several steps are involved in carrying a climate simulation with a GCM, and even more steps are required for dynamical downscaling using an RCM because an RCM requires driving boundary conditions (BC), both at the lateral boundary in the atmosphere (LBC) and at the surface over oceans (SST), and these can come either from reanalyses or from an archived GCM simulation. Figure 2 shows a flowchart describing the framework of our study.

After completing a long GCM simulation, GCM-projected climate changes (GCM_CC) are obtained by taking the difference between the projected future climate (GCM Future) and the simulated current climate (GCM Present), considering for example averages taken over 30 years. The ability of the GCM to faithfully reproduce the current climate is a necessary, but not sufficient, condition for the credibility of projected future climate changes (Patricola and Cook, 2010). The comparison of the GCM-simulated current climate (GCM Present) with some observational database provides a measure of the "GCM structural biases" (GCM_SB).

Two sets of simulations need to be performed with an RCM, one with driving boundary conditions from reanalyses and another from an archived GCM simulation. Comparing reanalysis-driven RCM simulations (RCM/ ERA) with some observational database provides a measure of the "RCM structural biases" (RCM_SB). In principle the RCM structural biases are expected to be smaller than the GCM structural biases, due to the higher resolution of RCM and to the fact that the RCM is driven by (nearly) perfect boundary conditions from reanalyses. On the other hand, when an RCM is driven by a GCM (RCM/GCM), the $\mathrm{RCM}$ simulations are affected by the combined effect of its own structural biases and of the imperfect $\mathrm{BC}$ (RCM_SB_BC). Comparing GCM-driven RCM simulations (RCM/GCM) with reanalysis-driven RCM simulations (RCM/ERA) provides a measure of the effect of the lateral and lower boundary conditions on the RCM simulation (BC_E = RCM_SB_BC - RCM_SB).

Climate changes are obtained from GCM-driven RCM simulations (RCM_CC) by taking the difference between the projected future climate (RCM/GCM Future) and the simulated current climate (RCM/GCM Present). Comparing a GCM-driven RCM simulation with the corresponding driving GCM simulation provides a measure of the "added value" afforded by dynamical downscaling with an RCM; note that while one hopes that the added value afforded by the higher resolution contributes to an improvement, it is possible that it may also constitute a deterioration. The added value may be studied under current climate conditions (RCM_AV_p), for future climate (RCM_AV_f), or for the climate changes themselves (CC_AV).

\subsection{Model description}

A detailed description of CRCM5 is given in HD12. CRCM5 is based on the limited-area model (LAM) configuration of the Canadian Global Environment Multiscale (GEM) model (Zadra et al. 2008). The physical parameterisations include the Kain and Fritsch (1990) deep-convection and Kuo-transient (Kuo 1965; Bélair et al. 2005) shallow convection schemes as well as the Sundqvist scheme for large-scale condensation (Sundqvist et al. 1989), the correlated-K scheme for solar and terrestrial radiations ( $\mathrm{Li}$ and Barker 2005), a subgrid-scale mountain gravity-wave drag (McFarlane 1987) and low-level orographic blocking (Zadra et al. 2003), a turbulent kinetic energy closure in the planetary boundary layer and vertical diffusion (Benoit et al. 1989; Delage and Girard 1992; Delage 1997), and a weak $\nabla^{6}$ lateral diffusion. 
The land-surface scheme of CRCM5 is the Canadian LAnd Surface Scheme (CLASS; Verseghy 2000, 2008) in its most recent version, CLASS 3.5. For these simulations 26 soil layers are used reaching to a depth of $60.0 \mathrm{~m}$, instead of the default three layers with the bottom at $4.1 \mathrm{~m}$ used in the simulation presented in HD12. Otherwise, as in HD12, the standard CLASS distributions of sand and clay fields as well as the bare soil albedo values were replaced by data from the ECOCLIMAP database (Masson et al. 2003). The interactive thermo-dynamical 1-D lake module (FLake model) was also used (see Martynov et al. 2010a, 2012a).

\subsection{Simulation configuration}

CRCM5 was integrated over the African domain recommended by CORDEX (Fig. 1) with a horizontal grid spacing of $0.44^{\circ}$, with a 20 -min timestep. The computational domain has $216 \times 221$ grid points, excluding the semi-Lagrangian halo but including a 10-grid-point wide sponge zone around the perimeter; hence the free domain is $196 \times 201$. In the vertical, 56 levels were used, with the top level near $10 \mathrm{hPa}$ and the lowest level at $0.996^{*} p_{s}$ where $p_{s}$ is the surface pressure. For diagnostic analysis the simulated fields were interpolated to 22 pressure levels $(1000,975,950,925,900,850,800,700,600,500,400$, $300,250,200,150,100,70,50,30,20,15$ and $10 \mathrm{hPa}$ ); most variables were archived at three hourly intervals, except precipitation and surface fluxes that were cumulated and archived at hourly intervals.

For the GCM-driven CRCM5 simulations the atmospheric lateral boundary conditions (LBC) and sea-surface temperatures (SSTs) came from two GCMs simulations for the period 1950-2100, under historical and RCP4.5 emission scenario. One GCM is MPI-ESM-LR, the Earth System version of the Max-Planck-Institut für Meteorologie coupled global climate model (http://www.mpimet.mpg.de/ en/science.html), with the atmospheric component operating at T63 with a quadratic transform grid of approximately $1.89^{\circ}$, and 47 levels in the vertical. The other is CanESM2, the Earth System version of the 4th generation Canadian coupled global climate model (http://www.ec.gc.ca/ccmaccccma/default.asp?lang=En\&n=3701CEFE-1; http://www. ec.gc.ca/ccmac-cccma/default.asp?lang=En $\& n=8 \mathrm{~A} 6 \mathrm{~F} 8$ F67-1), with the atmospheric component operating at T63 spectral resolution, with a linear transform grid of approximately $2.8^{\circ}$, and 35 levels in the vertical. Due to its coarser mesh, CanESM2 does not resolve the Red Sea and the Persian Gulf, and hence cannot provide SSTs to CRCM5 there; the CRCM5 Flake module with 60 m-depth was activated for those regions. For the ERA-driven CRCM5 simulations (as in HD12), LBC and SST came from the European Centre for Medium-range Weather
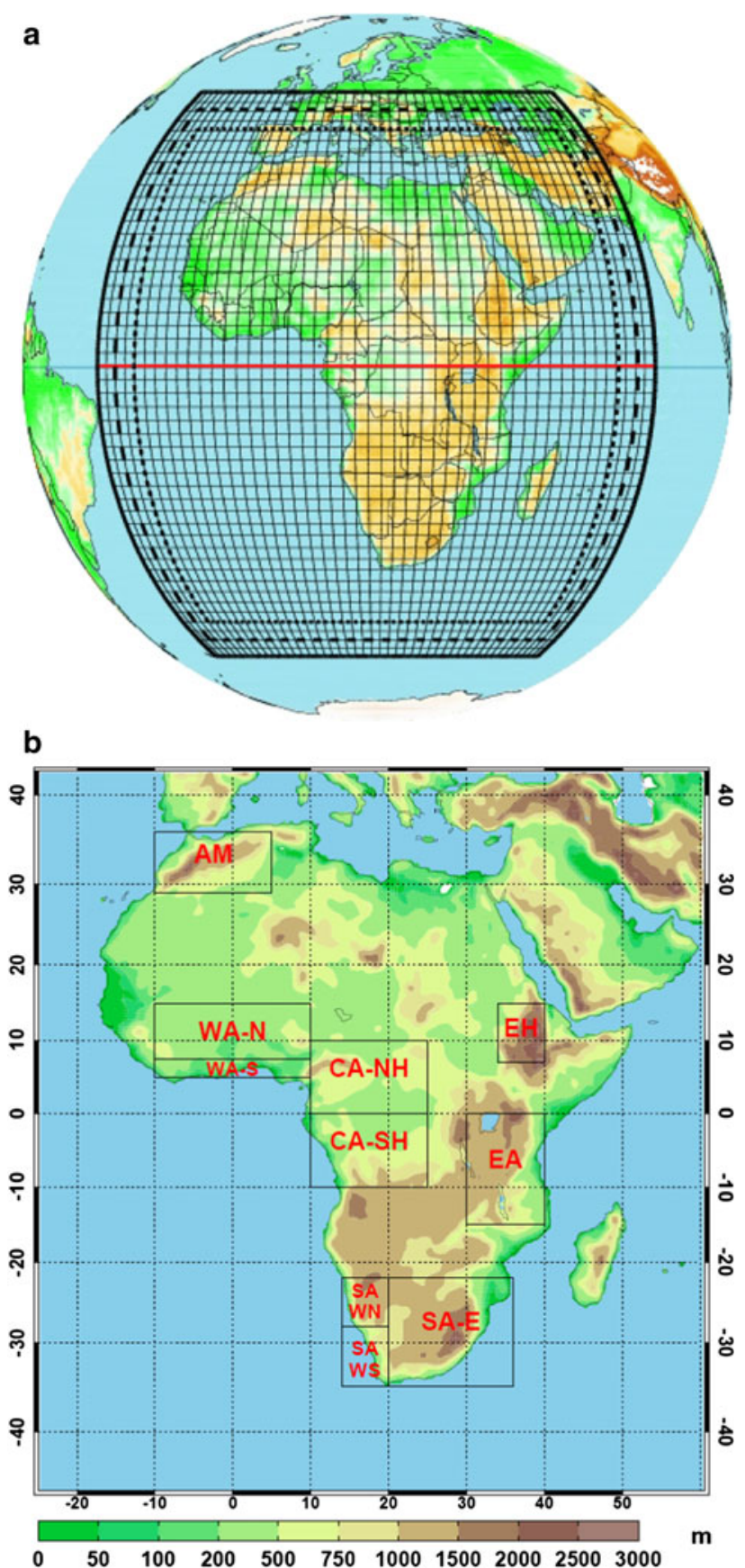

Fig. 1 a CRCM5 CORDEX-Africa simulation domain, including the semi-Lagrangian halo and Davies sponge zone; only every 5th grid box is displayed. b The different regions within the African domain are taken from http://www.smhi.se/forskning/forskningsomraden/ klimatforskning/1.11299

Forecasting (ECMWF) gridded reanalyses (ERA; Simmons et al. 2007; Uppala et al. 2008), for 1984-2008 (ERA-40 for pre-1989 and ERA-Interim for post-1989), available to us on a $2.0^{\circ}$ grid and 22 pressure levels.

The simulations will be compared to available observational datasets. This includes the CRU (Climate Research Unit, version 3.1 from 1901 to 2009; Mitchell 
and Jones 2005; Mitchell et al. 2004) and UDEL (University of Delaware, version 2.01: 1901-2008; Legates and Willmott 1990a, b; Willmott et al. 1998) gridded analyses at $0.5^{\circ}$ spatial and monthly temporal resolution, the GPCP dataset at $1^{\circ}$ daily (Global Precipitation Climatology Project; Adler et al. 2003) available from 1997 (Huffman et al. 2001), and the TRMM (Tropical Rainfall Measuring Mission; Huffman et al. 2007) dataset, at a resolution of $0.25^{\circ}$ at 3 hourly (3B42) and monthly intervals (3B43), covering the period from 1998 to present.

\section{Current climate results}

Before analysing climate projections, it is paramount to first study the performance of the models in simulating current climate, as model projections cannot be credible if models are unable to reproduce skilfully the current climate. In this section we focus on the results of simulations under current climate, corresponding to the orange section of the flowchart shown in Fig. 2. The period (1981-2010) will be considered as the reference or control period for the climate-change projections.

\subsection{Seasonal mean climatology}

As most of the African continent lies within the tropics, the seasonal migration of the tropical rainbelt, which regulates the alternation of wet and dry seasons, is an important characteristic of the climate. In boreal winter, the tropical rainbelt is at its southernmost position and the precipitation maximum lies mostly south of the equator. To the north, the continent is under the influence of the dry northeasterly winds. In boreal summer, the tropical rainbelt is at its northernmost location and the precipitation in confined essentially in a band north of the equator, reaching up to $15^{\circ} \mathrm{N}$ in the Sahel; in this season, the humid southwesterly monsoonal winds penetrate further north into the continent. These changes in circulation and precipitation are induced by the seasonal variations of the surface temperature contrast between land and ocean. In boreal summer the Sahara is very hot and the east equatorial Atlantic Ocean is colder than in boreal winter. The large-scale pressure gradient between the hot Sahara and the colder equatorial Atlantic Ocean brings the southerly flow from the ocean to the land and the West African Monsoon (WAM) precipitation into the Sahel. In fact, in boreal summer the two key players of the northern migration of the WAM rainfall are the thermal low located over the Sahara (the Saharan Heat Low, SHL), and the cold tongue present in the east equatorial Atlantic Ocean (e.g., Thorncroft et al. 2010; Lafore et al. 2010; Nguyen et al. 2011).

Figure 3 shows the SST bias of the two GCMs for current climate (1989-2008), in boreal winter (JFM) and boreal summer (JAS). The most striking feature is the warm bias in the Guinea Gulf and the tropical Atlantic Ocean along the West Coast of the continent southward of the equator in JAS; in fact in both GCMs this bias extends quite far off the African coast (not shown), which certainly introduces biases in the atmospheric circulation serving as LBC to CRCM5. Both models fail to represent properly the cold tongue that develops in boreal spring (AMJ, not shown) and reaches its maximum intensity in JAS. As it is the development of the cold tongue in spring and its reinforcement in summer that, combined with the evolution of the SHL and its associated Shallow Meridional Circulation (SMC), brings the WAM rainfall from the equator to the Guinea Coast region in spring and later over the Sahel region in summer, this SST bias will have repercussions on the GCM-driven CRCM5 simulations of the WAM, as will be shown later.
Fig. 2 Flowchart of the experiment design

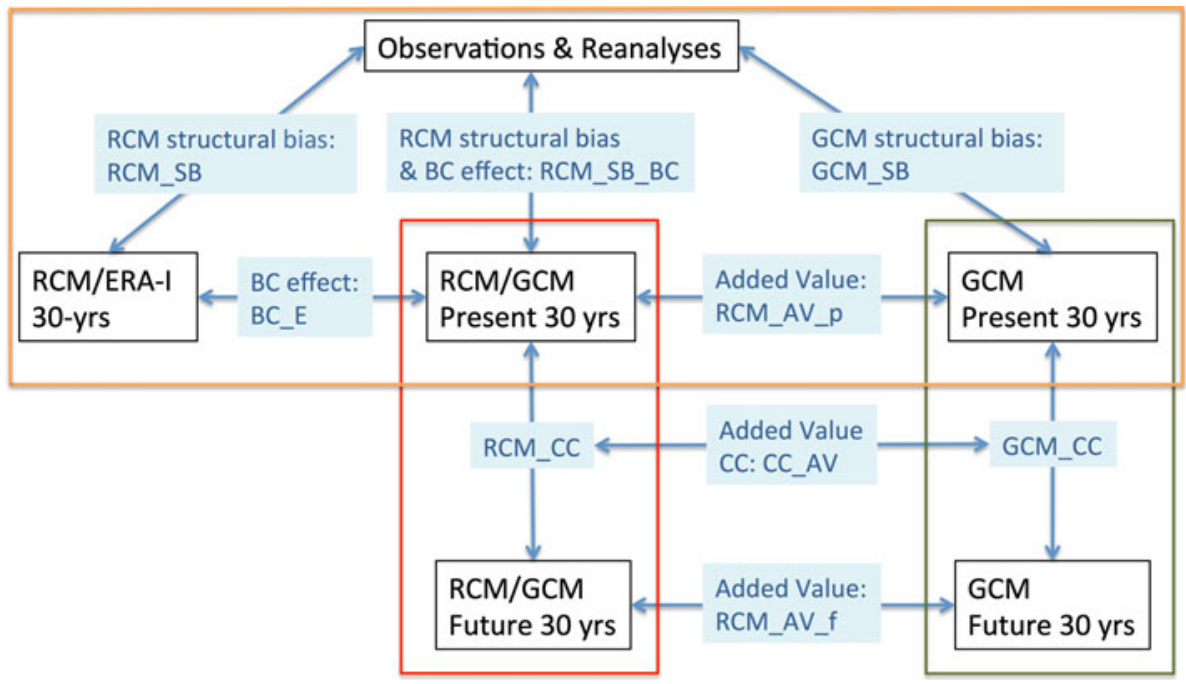



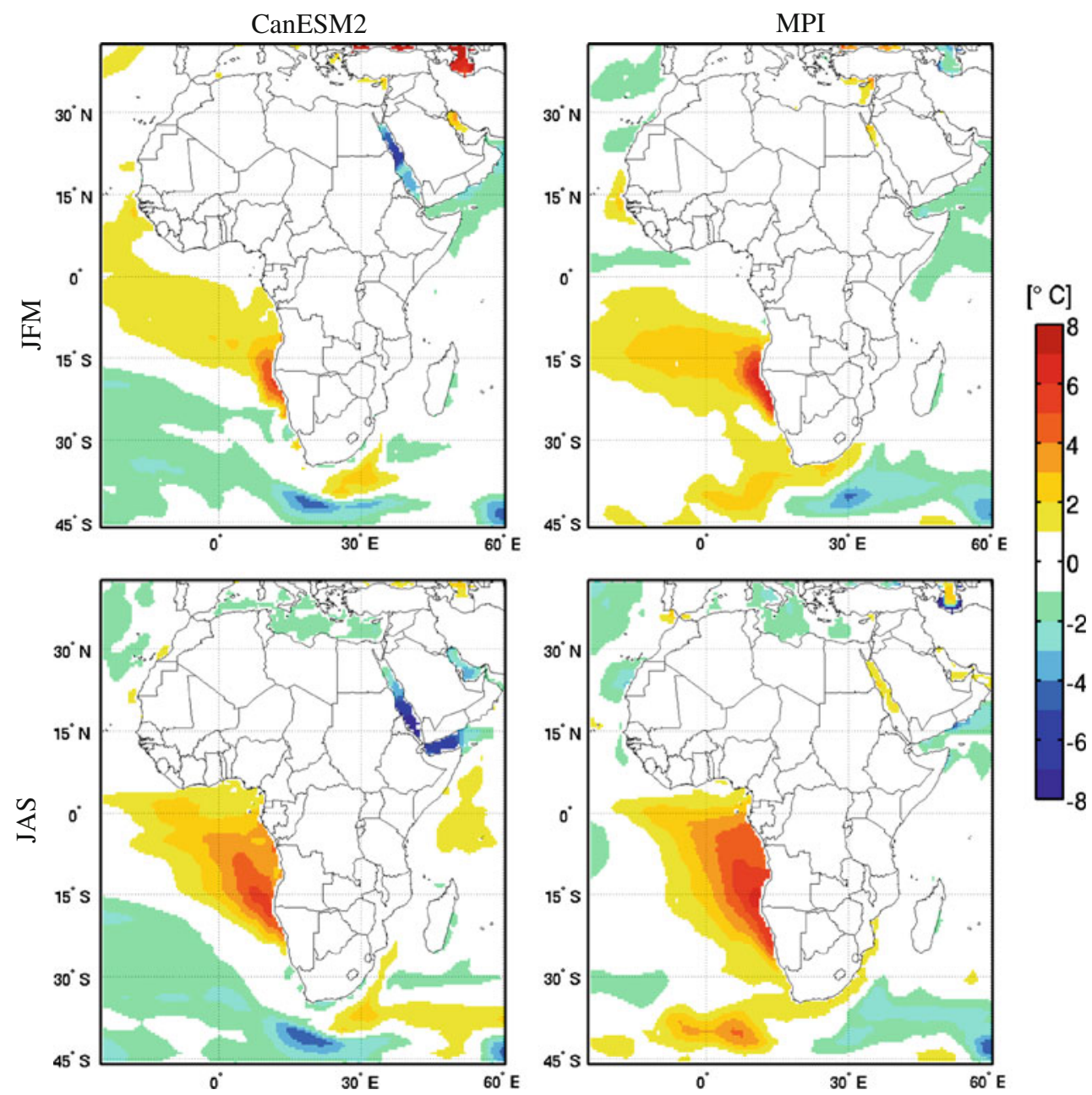

Fig. 3 Sea surface temperature bias in JFM (top) and JAS (bottom) for current climate (1989-2008) for CanESM2 (left) and MPI (right)

In order to capture at a glance the performances of the models in current climate we show results for the JFM and JAS seasonal-mean 2-m air temperature for the 20-year CORDEX period 1989-2008 (Fig. 4); for precipitation (Fig. 5), a shorter period 1997-2008 is used due to limitations in the availability of observational datasets. In both figures, top left panels show one source of observation used as reference; all other panels except rows three and five show biases as departure from this reference. Top right panels show the structural bias of the ERA-driven CRCM5 simulation (RCM_SB) that was extensively analysed in HD12. The second row shows the GCM-driven RCM bias resulting from the combined effects of CRCM5 structural bias and the lateral and lower boundary conditions (RCM_SB_BC) when driven by CanESM2 (left) and MPI (right). The third row shows difference between the GCMdriven and ERA-driven CRCM5 simulations, reflecting the impact of lateral and lower boundary errors on the CRCM5 simulation (BC_E) when driven by CanESM2 (left) and MPI (right); this field is in fact equal to the difference between RCM_SB_BC and RCM_SB. The fourth row shows the bias of the driving GCMs (GCM_SB), CanESM2 on the left and MPI on the right. Finally the fifth row shows the difference between the GCM-driven CRCM5 and the driving GCM simulations (RCM_AV_p), which kind of constitutes the CRCM5 added value under current climate, again when driven by CanESM2 (left) and MPI (right); this field is in fact equal to the difference between RCM_SB_BC and GCM_SB. For the temperature (Fig. 4) only the third and fifth rows show the differences over the oceans.

Compared to CRU analysed 2-m temperatures, there is a slight cold bias in the ERA-driven CRCM5 simulation in JFM (Fig. 4a: RCM_SB) over most of the domain south of the equator, as well over a part of the West Africa region. On the other hand, there is a warm bias near the border between the Central African Republic and the Democratic Republic (DR) of Congo. The MPI-driven CRCM5 simulation exhibits a stronger cold bias that occupies a larger region (RCM_SB_BC: MPI), as confirmed by the panel 
Fig. 4 Mean (1989-2008) 2-m temperature in $\mathbf{a}$ JFM and $\mathbf{b}$ JAS seasons from (1) observations (CRU, top left) and the CRCM5/ ERA bias (top, right). Also shown are (2) the CRCM5/ GCM bias and (3) the effect of lower and lateral boundary conditions when CRCM5 is driven by CanESM2 (left) and MPI (right) GCMs, (4) the GCMs bias (left, CanESM2 and right, MPI), and finally the CRCM5 added value (left, driven by CanESM2, and right by MPI) (a) JFM
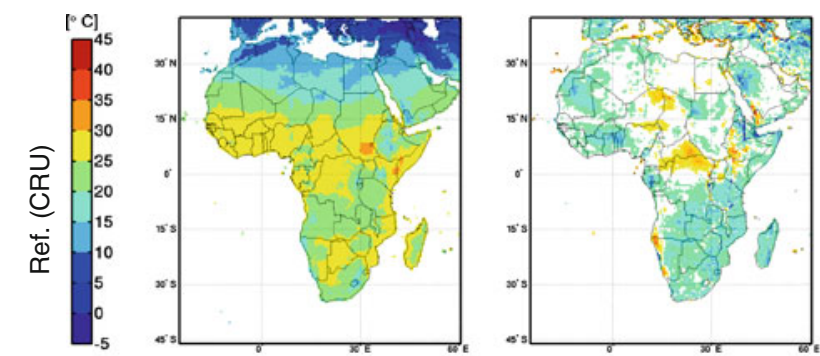

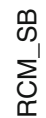
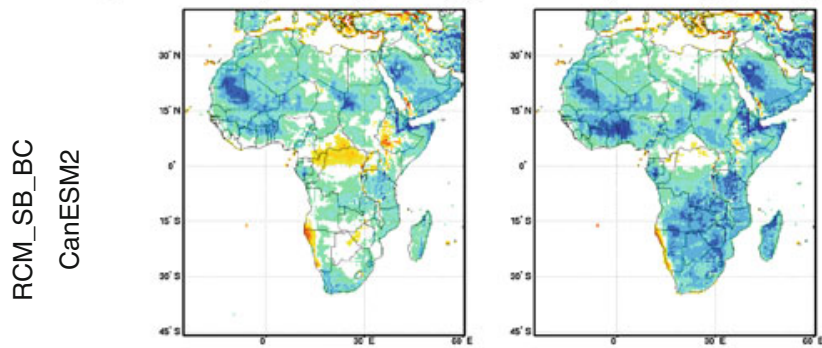

u

क

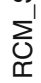

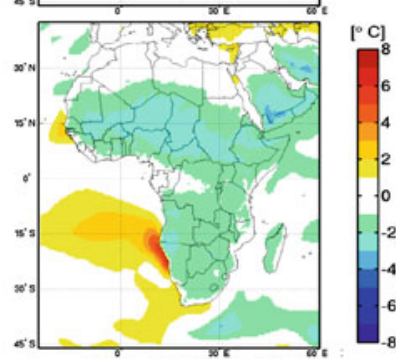

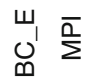

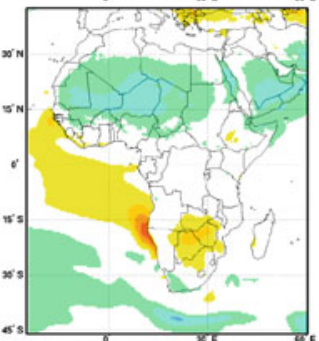

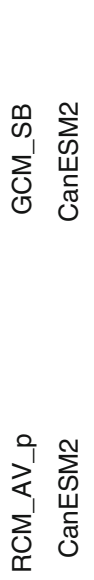

BC_E: MPI showing the difference between the MPI-driven and the ERA-driven CRCM5 simulations. The MPI GCM exhibits a strong cold bias over the Guinea Coast states and a warm bias in a narrow band along the southwest coast of Africa (GCM_SB: MPI); the CRCM5 is almost neutral at correcting the cold bias, but succeeds at correcting part of the warm bias, as can be seen in RCM_AV_p: MPI. On the other hand, the ERA-driven CRCM5 weak cold bias over the Sahara combines with the equally weak cold bias of the MPI GCM there, and results
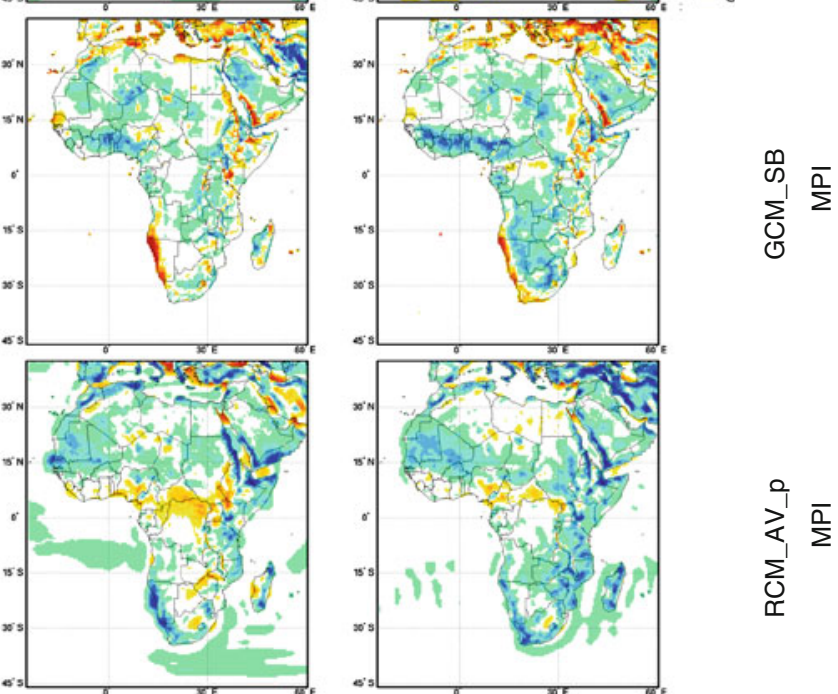

somehow in a stronger cold bias in MPI-driven CRCM5. Compared to the ERA-driven simulation the CanESM2driven CRCM5 simulation exhibits stronger cold bias over most of West Africa but a reduced cold bias south of the equator, and in fact almost no bias over Botswana, Zimbabwe and Zambia, which is better than ERA-driven simulation, possibly because BC_E: CanESM2 cancels the RCM_SB.

In JAS (Fig. 4b), ERA-driven CRCM5 exhibits a cold bias over the East Africa Highlands, the elevated terrains of 
Fig. 4 continued (b) JAS
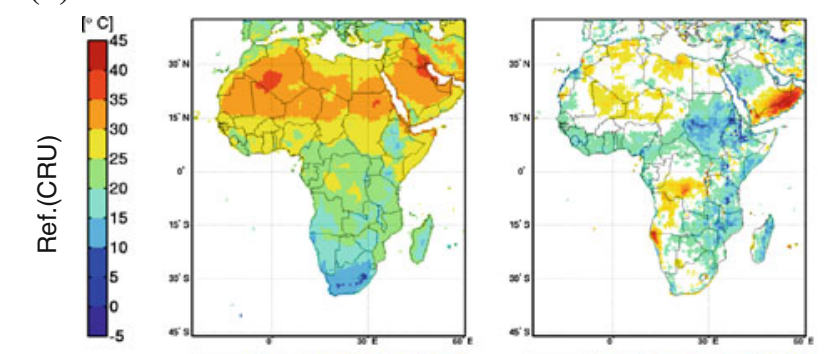

$\sum_{\substack{x \\ \infty}}^{\infty}$

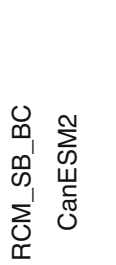

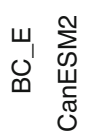
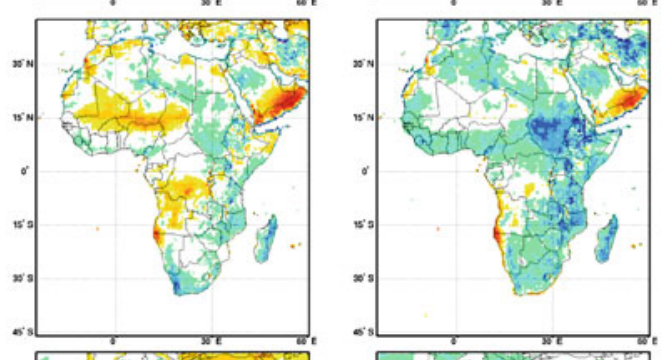

O

क

$\sum_{\substack{1 \\ \mathbb{1}}}$ $\sum_{0}^{\infty} \bar{c}$

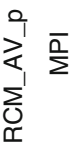
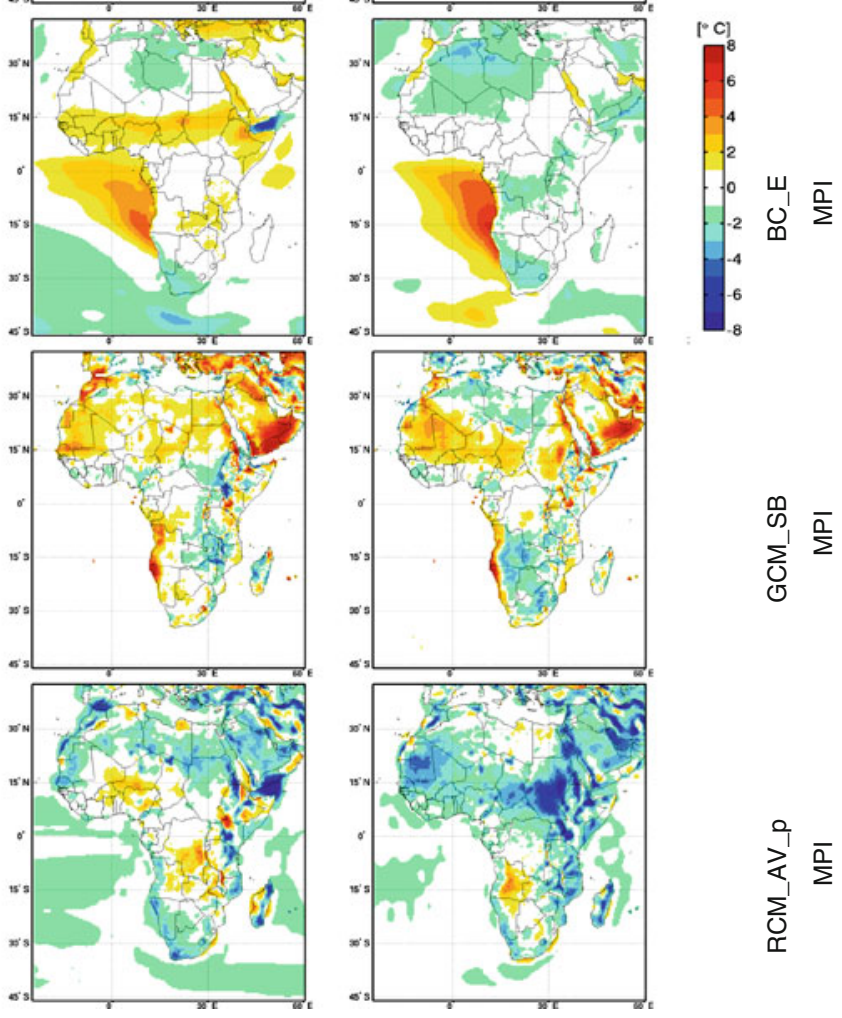

Ethiopia and Sudan, eastern Madagascar, and over the coastal countries of the Gulf of Guinea when compared to CRU (and UDEL, not shown). On the other hand, the model is slightly warmer than CRU in regions such as the Sahara, the apparent warm bias reaching up to $2{ }^{\circ} \mathrm{C}$ in regions such as the southern Congo basin and Oman. It is worth mentioning however that when comparing with ERA-Interim reanalyses or UDEL dataset, the CRCM5 simulation has a weak cold bias over the Sahara rather than a warm bias as noted in the comparison with CRU data (see the related discussion in HD12). Both GCMs exhibit a generalised warm bias over the continent (GCM_SB: Can and GCM_SB: MPI). With the exception of the cold bias in the Guinea Gulf Coast region which is peculiar to the CRCM5 and that is still present when driven by the two GCMs, everywhere else the GCMs warm bias is partly corrected by the CRCM5, as can be seen in RCM_AV_p.

The skill of the models in simulating seasonal mean precipitation, using GPCP as reference, is presented in Fig. 5 (a: JFM; b: JAS). In JFM the ERA-driven CRCM5 simulation has a rather small bias. Precipitation over the equatorial Atlantic Ocean is overestimated by both GCMs and the maximum is displaced southward, as seen in GCM_SB. When driven by GCMs, CRCM5 improves the 
Fig. 5 Mean (1997-2008) precipitation in a JFM and b JAS seasons from (1) observations (GPCP, top left) and the CRCM5/ERA bias (top, right). Also shown are (2) the CRCM5/GCM bias and (3) the effect of lower and lateral boundary conditions when CRCM5 is driven by CanESM2 (left) and MPI (right) GCMs, (4) the GCMs bias (left, CanESM2 and right, MPI), and finally the CRCM5 added value (left, driven by CanESM2, and right by MPI) (a) JFM

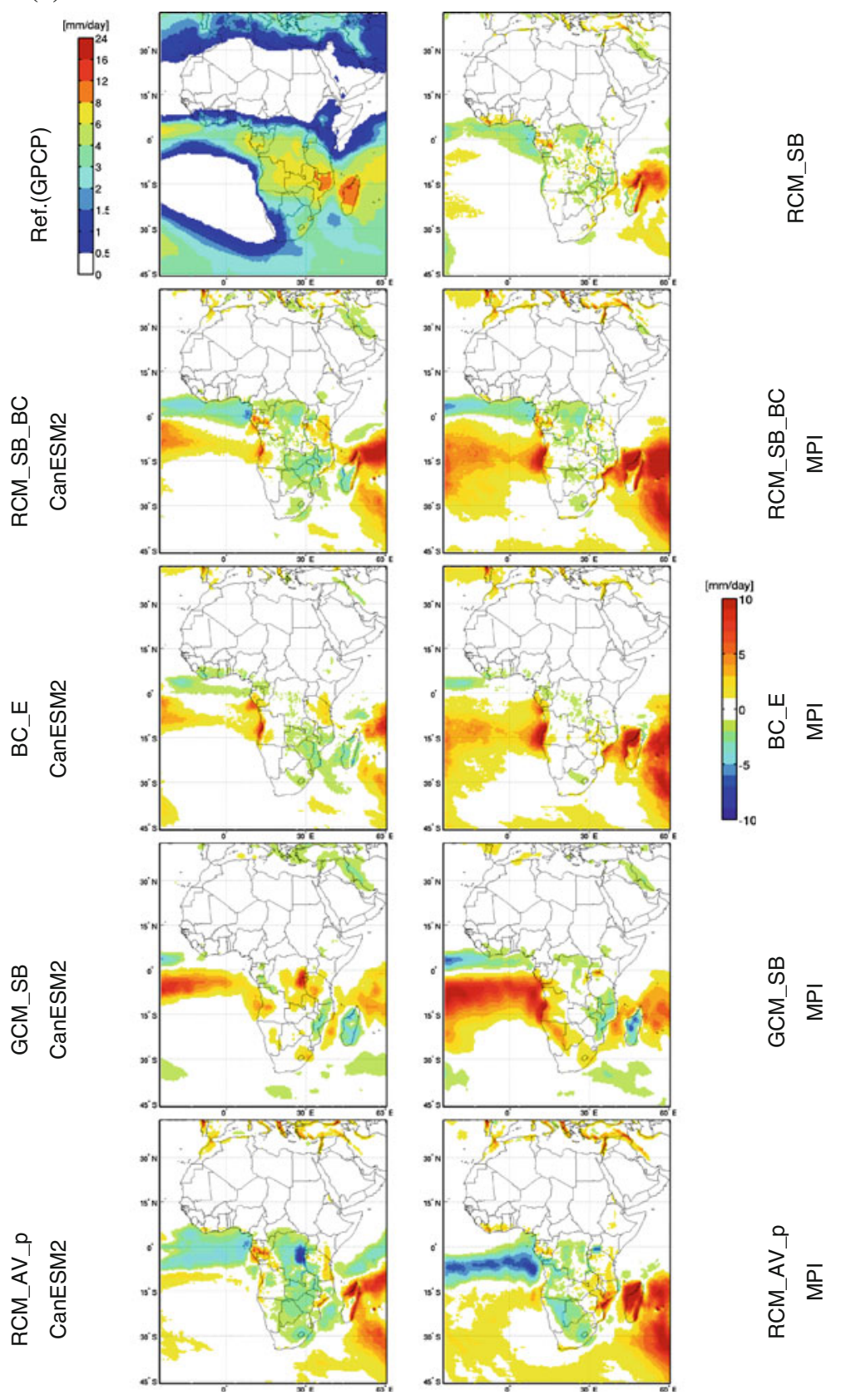

tropical rainbelt compared to the driving GCMs, as seen in RCM_AV_p that has overall the opposite sign of GCM_SB. On the other hand, the ERA-driven CRCM5 dry bias in the Gulf of Guinea coast remains in all GCM-driven CRCM5 simulations, and is in fact amplified although only MPI has also a dry bias there. There is a wet bias east of Madagascar in the ERA-driven CRCM5 simulation (RCM_SB) and a general dry bias over Madagascar in both GCMs; the wet bias is in fact intensified in the GCMdriven CRCM5 simulations, as confirmed in BC_E.

In JAS, the ERA-driven CRCM5 has a dry bias in the Sahel region and in the DR of Congo, as well as in a small region of the Guinea Gulf (RCM_SB). A dry bias in the Sahel is also present to some extent in the MPI simulation (GCM_SB: MPI). The CRCM5 dry bias remains when driven by MPI (RCM_SB_BC), and is amplified when driven by CanESM2 as confirmed by the difference field BC_E: CanESM2. Both GCMs exhibit a wet bias over the Guinea Gulf (GCM_SB), larger in MPI. This wet bias is associated to the GCM-simulated SST biases. In both GCM-driven CRCM5 simulations, the GCM wet bias is further propagated to the Guinea Gulf Coast states. On the other hand the CRCM5 reduces the wet bias over the ocean, as seen in RCM_AV_p that has the opposite sign to 
Fig. 5 continued

(b) JAS
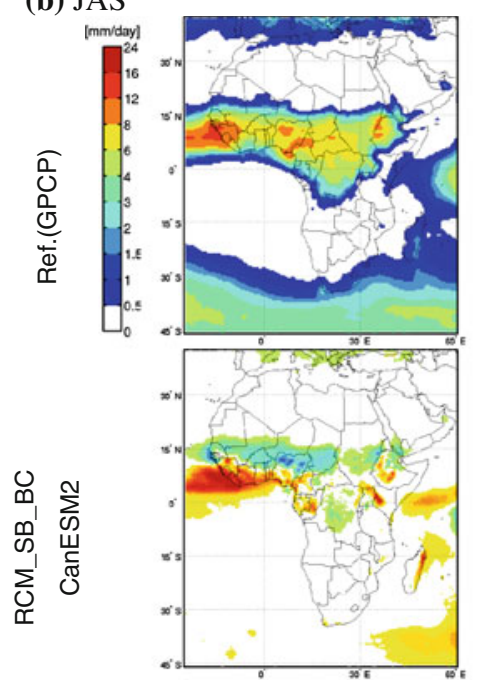

س

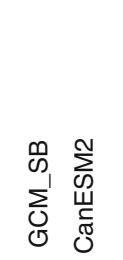

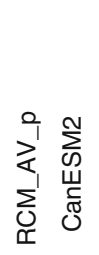

GCM_SB. CRCM5 also corrects the MPI dry bias in the South Sudan (GCM_SB: MPI), as can be seen from RCM_AV_p: MPI and RCM_SB_BC: MPI. Interesting, the CanESM2-driven CRCM5 has a dry bias in this region (RCM_SB_BC: Can) while its driving GCM has a wet bias (GCM_SB: Can).

\subsection{Annual cycle of precipitation}

Figure 6 displays the mean annual cycle of precipitation for some of the African-CORDEX regions shown in Fig. $1 \mathrm{~b}$. The observed annual cycle from three different datasets

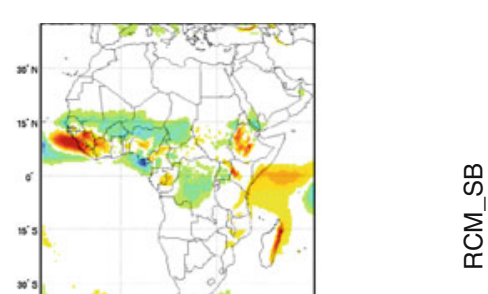

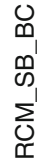
$\sum_{\substack{\infty \\ \infty}}^{\infty}$

(CRU, GPCP and TRMM), as well as from the ERA-driven CRCM5 simulation, are shown in addition to the CanESM2- and MPI-driven CRCM5 simulations, as well as CanESM2 and MPI simulations. The equatorial regions (CA-NH, CA-SH and WA-S) have two rainy seasons because of the double passage of the tropical rainbelt. This is well accounted for by all models in CA-SH and CA-NH, although with some errors in timing and intensity; for these regions, the GCM-driven CRCM5 simulations are better than the driving GCM. For the WA-S region, only the ERA-driven CRCM5 simulation succeeds in representing the bimodal distribution of precipitation with two maxima, 

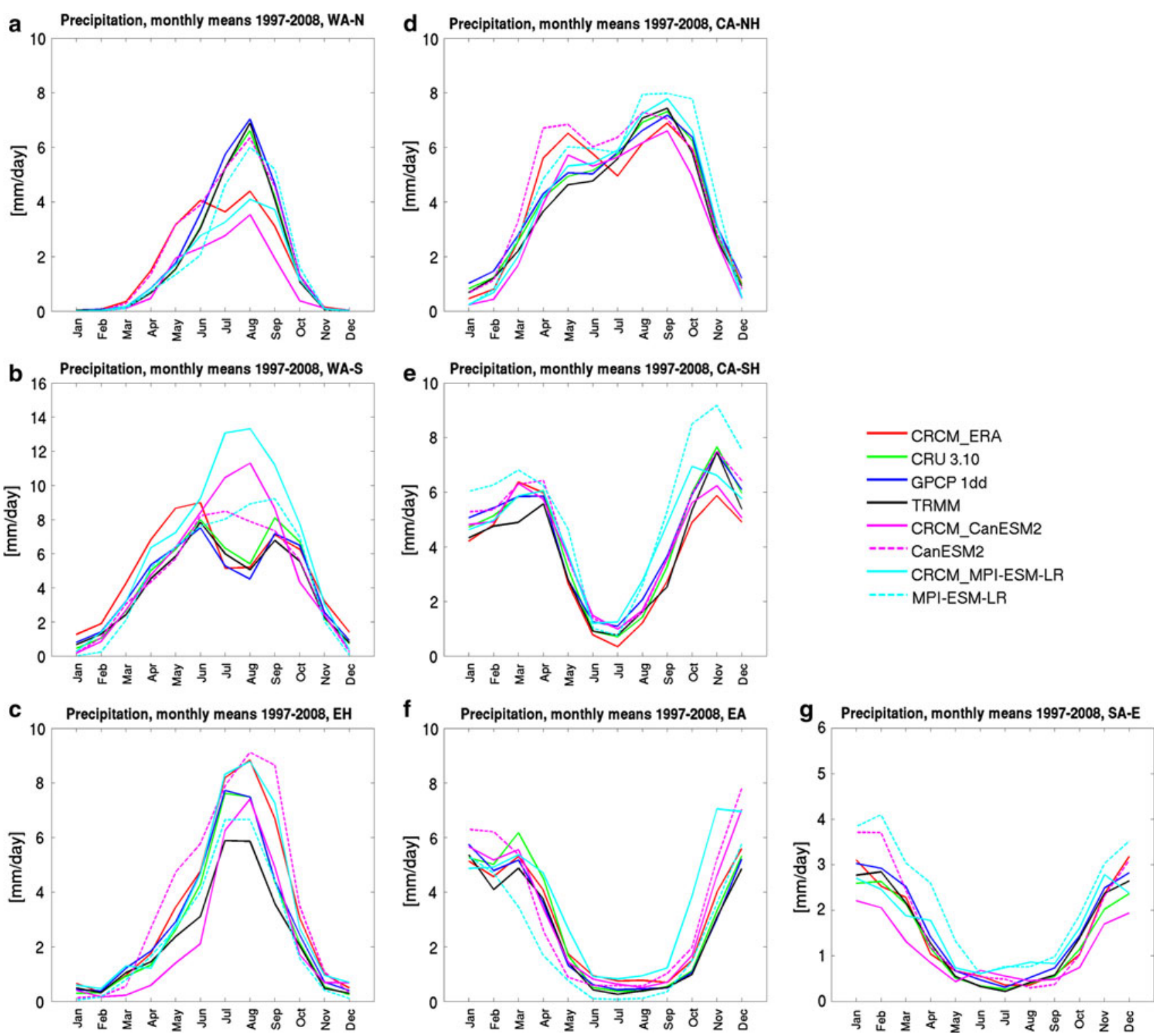

Fig. 6 Mean (1997-2008) annual cycle of precipitation (mm/day) from CRCM5/ERA (red), CRU (green), GPCP (blue), TRMM (black), CRCM5/CanESM2 (magenta), CRCM5/MPI (cyan), CanESM2 (dashed magenta) and MPI (dashed cyan) for the regions of the African CORDEX domain: a West Africa-North (WA-N), b West Africa-South

in AMJ and ASO. Both GCMs, as well as the GCM-driven CRCM5 simulations, miss this feature and show instead a single maximum of precipitation in JAS. Both GCMs overestimate the rainfall amounts in the WA-S region, and this wet bias is amplified in the GCM-driven CRCM5 simulations. In all the other regions however the GCMdriven CRCM5 simulations improve upon the GCM simulated annual cycle. An exception is the region of the Sahel (WA-N) where MPI and CanESM2 show a better representation of the annual cycle compared to CRCM5; this however appears to be due to a compensation of errors resulting from SST biases and coarse resolution.
(WA-S), c Ethiopian Highlands (EH), d Central Africa-Northern Hemisphere (CA-NH), e Central Africa-Southern Hemisphere (CA$\mathrm{SH})$, f East Africa (EA), $\mathbf{g}$ South Africa-East (SA-E). Note that TRMM period is (1998-2008)

\subsection{Diurnal cycle of precipitation}

The diurnal cycles in CRCM5 simulations driven by ERA, CanESM2 and MPI, are compared to that of the TRMM dataset for the period (1998-2008) in the same regions (Fig. 7). It is well known that maximum precipitation in tropical climates tends to occur in the evening or overnight rather than in the afternoon as in mid-latitudes. The proper simulation of the diurnal cycle over regions of the African continent is one of the most difficult tasks for the climate models (e.g., Nikulin et al. 2012). The CRCM5 simulates fairly well the diurnal cycle of precipitation in 

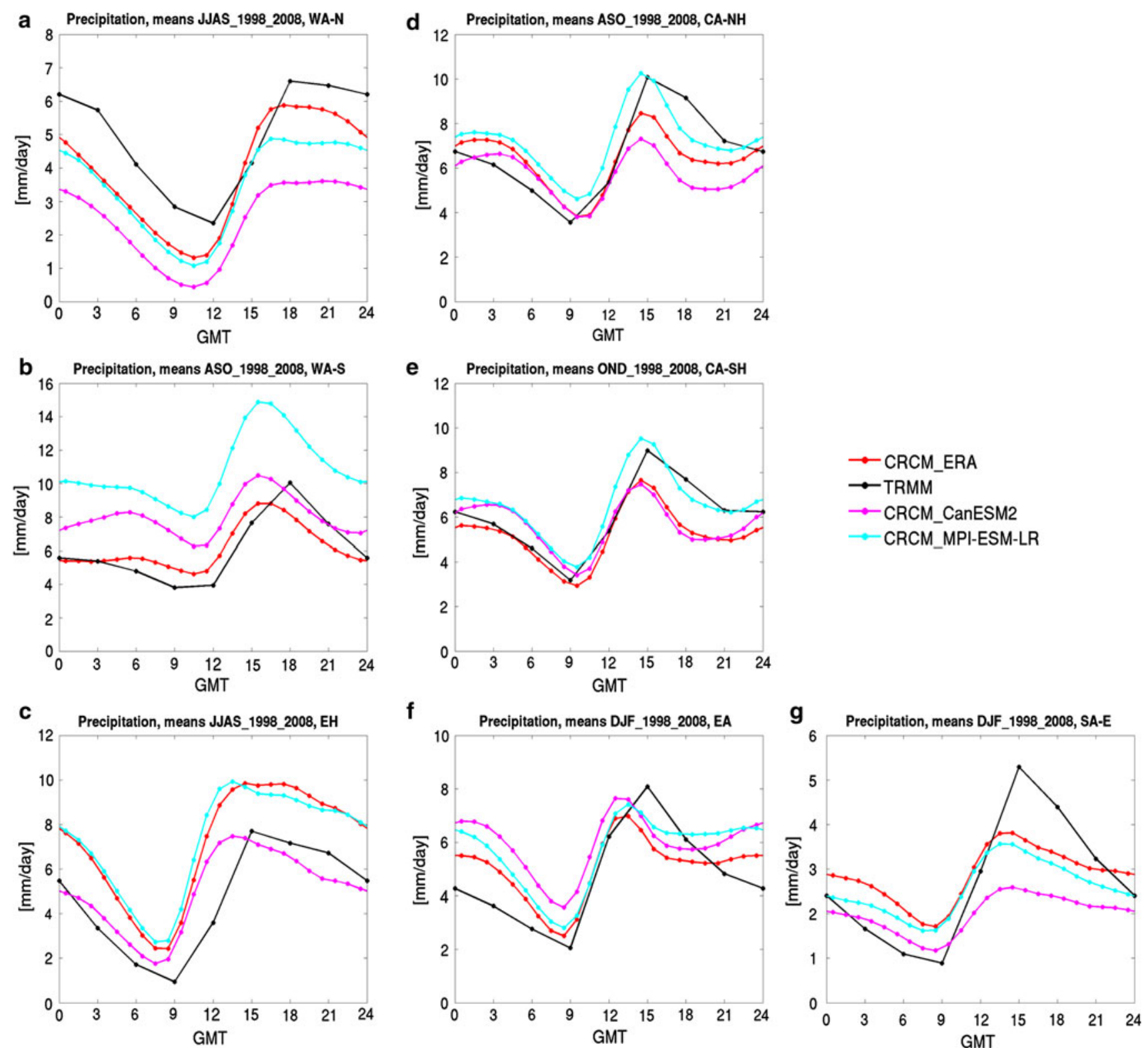

Fig. 7 Mean (1998-2008) diurnal cycle of precipitation from TRMM dataset (black) as well as CRCM5/ERA (red), CRCM5/CanESM2 (magenta) and CRCM5/MPI (cyan) over regions of the African CORDEX domain: a West Africa-North (WA-N), b West Africa-

South (WA-S), c Ethiopian Highlands (EH), d Central AfricaNorthern Hemisphere (CA-NH), e Central Africa-Southern Hemisphere (CA-SH), f East Africa (EA), g South Africa-East (SA-E)

most of the regions, with some tendency for precipitation maximum somewhat early rather independently of the driving data except for two equatorial regions: $\mathrm{CA}-\mathrm{NH}$ and CA-SH. The MPI-driven CRCM5 simulation does particularly well in these two equatorial regions, $\mathrm{CA}-\mathrm{NH}$ and CA-SH, but overestimates the precipitation amounts in WA-S. In the WA-N region, the MPI-driven CRCM5 simulation does better than the CanESM2-driven one, and this is also true for the SA-E region. In the $\mathrm{EH}$ region the CanESM2-driven CRCM5 simulation performs better, although the shape of the cycle is displaced to an earlier rainfall peak. Finally, in the EA region the simulated diurnal cycles are very close.

\subsection{Daily precipitation intensity distributions}

Figure 8 shows the distribution, by range of intensities, of the contributions to daily precipitation amounts (hereinafter called the daily precipitation intensity distribution, DPID), from the three CRCM5 simulations and the two GCMs simulations, as well as from the TRMM observational dataset for the period (2001-2008) for the same 

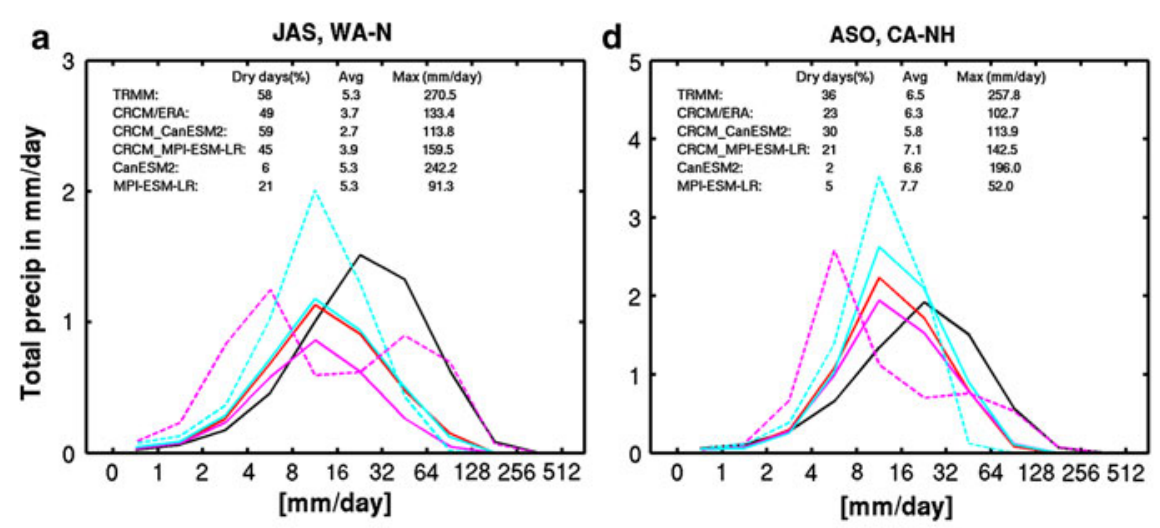

ASO, WA-S
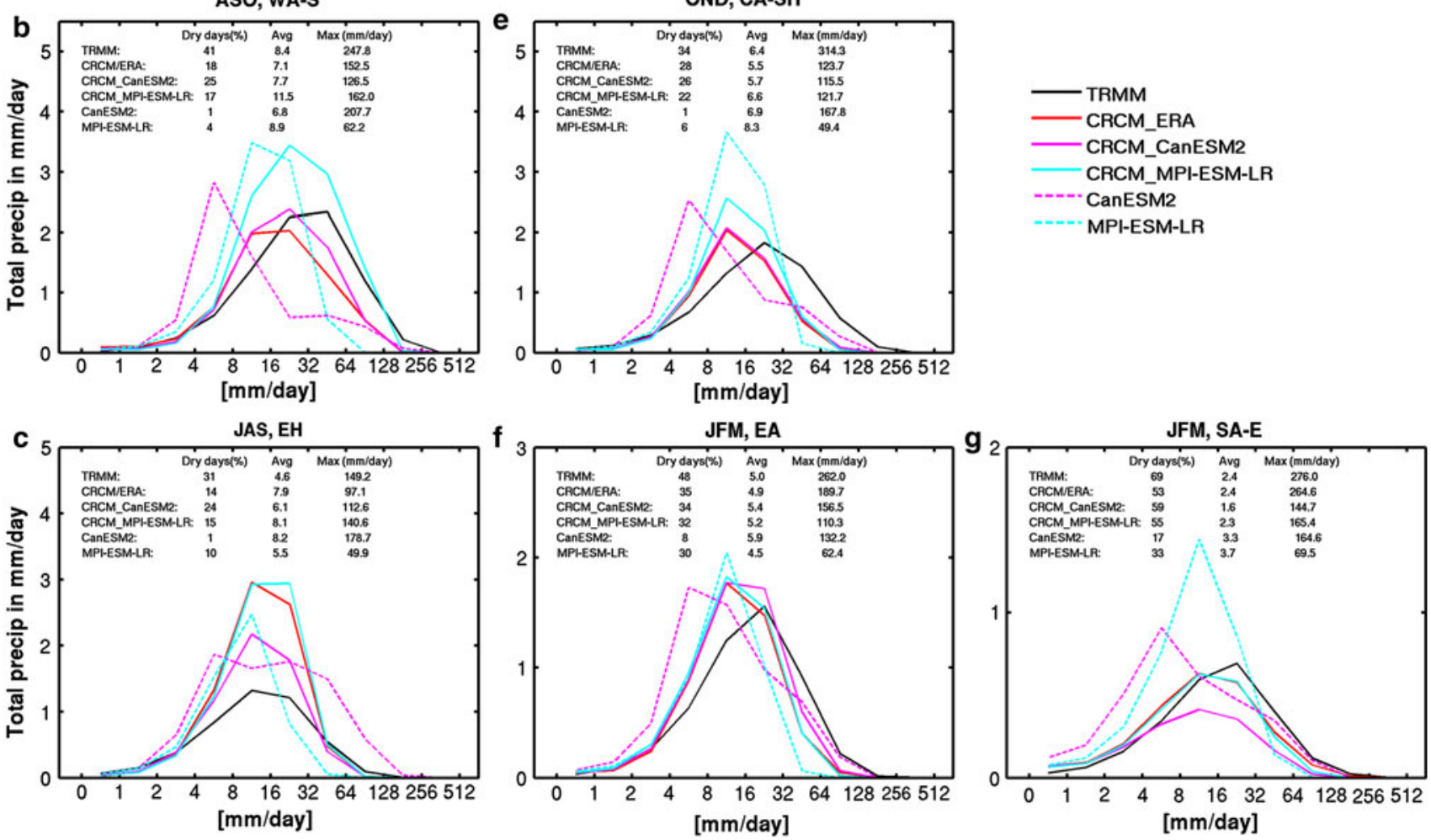

Fig. 8 Mean (2001-2008) daily precipitation intensity distribution (DPID) as simulated by CRCM5/ERA (red), CRCM5/CanESM2 (magenta), CRCM5/MPI (cyan), CanESM2 (dashed magenta), MPI (dashed cyan), as well as from TRMM observational dataset (black), over regions of the African CORDEX domain: a West Africa-North

regions of Figs. 6 and 7. These figures in fact should be drawn as histograms, but are shown as curves for ease of comparison between several datasets. These figures are designed such that the sum of all the bins gives the daily average precipitation. For example, in WA-N in JAS (Fig. 8a) the MPI model (in dashed cyan) has a value of $2 \mathrm{~mm} /$ day ( $Y$ axis) in the range of daily precipitation intensities from 8 to $16 \mathrm{~mm} /$ day ( $X$ axis); this corresponds to $184 \mathrm{~mm}$, i.e. $2 \mathrm{~mm}$ /day multiplied by 92 days for JAS. The JAS mean precipitation amount is $487.6 \mathrm{~mm}$, that is the product of the number of days (92) times the average daily precipitation $(5.3 \mathrm{~mm} /$ day $)$ shown in the upper left corner of
(WA-N), b West Africa-South (WA-S), c Ethiopian Highlands (EH), d Central Africa-Northern Hemisphere (CA-NH), e Central AfricaSouthern Hemisphere (CA-SH), f East Africa (EA), g South AfricaEast (SA-E). The time of the year is chosen to correspond to a wet season for each region

the graphic. In other words, the range of daily precipitation intensities from 8 to $16 \mathrm{~mm} /$ day contributes for a fraction of $2 / 5.3$ to the total precipitation.

For the WA-N region (Fig. 8a) although CanESM2 and MPI succeed in reproducing the average precipitation of the observations $(5.3 \mathrm{~mm} /$ day $)$, the DPID are very different, CanESM2 even exhibiting a bimodal distribution that is inexistent in the observations. In MPI and all the CRCM5 simulations, there is displacement of the maximum contribution toward smaller daily intensities (8-16 $\mathrm{mm} /$ day) with respect to observations (16-32 $\mathrm{mm} /$ day). Overall MPI shows a better distribution than CanESM2. 
The CRCM5 simulations have similar shapes to the observed distribution although with smaller average precipitation amounts. We recall that we saw in Fig. 6a that CanESM2 and MPI showed the best match with the observed annual cycle of precipitation in WA-N; their DPID however differ very much from the observations.

For the WA-S region (Fig. 8b) the ERA- and CanESM2driven CRCM5 simulations have the best distributions. In fact, the DPID of CRCM5 is better than that of its driving model. The improvement is less remarkable in the case of the MPI-driven CRCM5 with respect to MPI. For the other two equatorial regions (CA-NH and CA-SH) (Fig. 8d, e) all the CRCM5 simulations (ERA- and GCM-driven) have similar DPID and best match the observed DPID. In these regions also the CRCM5 considerably improves upon the corresponding driving GCMs DPID. The same is true for the SA-E region (Fig. 8g). In this case however the CanESM2-driven CRCM5 shows a somewhat flattened distribution.

The DPID of the two GCM-driven and the ERA-driven CRCM5 simulations are very similar in the EA region (Fig. 8f), improving upon that of the corresponding driving GCMs. The situation is somehow different in the EH region (Fig. 8c) where although CanESM2-driven CRCM5 still improves upon CanESM2, the peak of the distribution is overestimated with respect to that of the observations, but less than those of the very similar ERA-driven and MPI-driven CRCM5 simulations. It is worth to note that in this region the TRMM showed smaller amounts of precipitation than the other observational datasets (GPCP and CRU) as was seen in Fig. 6c.

Finally a recurrent feature of the CanESM2 in all regions is a bias of the precipitation distribution towards lower intensities and even occasionally a bimodal distribution that is not found in the observations; the CanESM2driven CRCM5 simulation is able to correct this deficiency.

\subsection{West African monsoon}

As the WAM is one of the most important elements of the African climate, this section is dedicated to the analysis of the performance of the climate models employed in this study in simulating the WAM. Hovmöller-type diagrams presented in Fig. 9 show time-latitude cross-sections of daily precipitation, averaged over $10^{\circ} \mathrm{W}-10^{\circ} \mathrm{E}$ for the period 1997-2008, from GPCP data, as well as from the CRCM5 simulations driven by ERA, CanESM2 and MPI, and from the CanESM2 and MPI simulations. A 31-day moving average has been applied to remove high-frequency variability. It can be noted that only the ERA-driven CRCM5 simulation succeeds in reproducing the seasonal migration of the WAM precipitation, with a first peak in the Guinea Coast in May (around $5^{\circ} \mathrm{N}$ ) and a second one in the Sahel region (around $10^{\circ} \mathrm{N}$ ) in August. The ERA-driven CRCM5 simulation also reproduces the second rainy season of the Guinea Coast region in September. The two GCMs fail to reproduce this pattern as they show essentially only the maximum around $10^{\circ} \mathrm{N}$. The two GCM-driven CRCM5 simulations suffer from the same handicap as their driving GCM, producing only one rainy season from the coast up to $10^{\circ} \mathrm{N}$ and with higher intensities, the MPI-driven simulation being the most intense. The GCM precipitation peak at $5^{\circ} \mathrm{N}$ occurs much later in the season than in the observations; given the coarse mesh of the GCM, this peak is probably simply an extension of nearby ocean precipitation rather than the beginning of the continental rainy season. In other words, the bimodality of the rainy season in the Gulf of Guinea coast, present in the ERA-driven CRCM5 simulation, disappears when driven by the GCMs and is also absent in the GCMs. This is related to the misrepresentation of the seasonal cycle of the GCM-simulated SSTs in the equatorial Atlantic Ocean (see Fig. 3). Furthermore CanESM2 shows precipitation too far north, beyond $20^{\circ} \mathrm{N}$, while MPI gives a better representation closer to the observed values (between $15^{\circ} \mathrm{N}$ and $20^{\circ} \mathrm{N}$ ). On the other hand, all of the CRCM5 simulations barely go beyond $15^{\circ} \mathrm{N}$. The dry bias of reanalyses-driven CRCM5 in the Sahel region (as noted in HD12) remains when driven by CanESM2 and MPI, as can be seen also in Figs. 5b, and 6a.

The seasonal-mean vertical cross-sections of the mean zonal wind from $10^{\circ} \mathrm{S}$ to $35^{\circ} \mathrm{N}$, averaged between $10^{\circ} \mathrm{W}$ and $10^{\circ} \mathrm{E}$, is presented in Fig. 10; the left column shows the CRCM5 driven by ERA, CanESM2 and MPI, and the right column the corresponding driving data. The main features of the WAM circulation are represented in all simulations, although with more or less success; this includes the cooler and humid southwesterly monsoonal winds and the hot and dry easterly winds in the low levels, the African Easterly Jet (AEJ) in the mid levels, and the Tropical Easterly Jet (TEJ) in the upper troposphere. The monsoonal winds reach $20^{\circ} \mathrm{N}$ in the reanalyses while in CanESM2 and MPI they only reach $18^{\circ} \mathrm{N}$. The shape of the dome they form are also different, MPI being the nearest to the reanalyses. The CRCM5 simulations also show a somewhat different shape of monsoonal winds when compared to their driving data. The surface convergence between the monsoonal and easterly winds is located further south (by almost $2^{\circ}$ ) in the CRCM5 simulations compared to the driving data, and the same is valid for the position of the AEJ. The core of the AEJ is nearly at the right height and intensity in almost all of the CRCM5 simulations, but it is smaller in the CanESM2-driven CRCM5 simulation. On the other hand, it is oversized in the MPI model, but better represented in the MPI-driven CRCM5 simulation. The southward bias in the position of the AEJ is thus present not only in the ERA- 

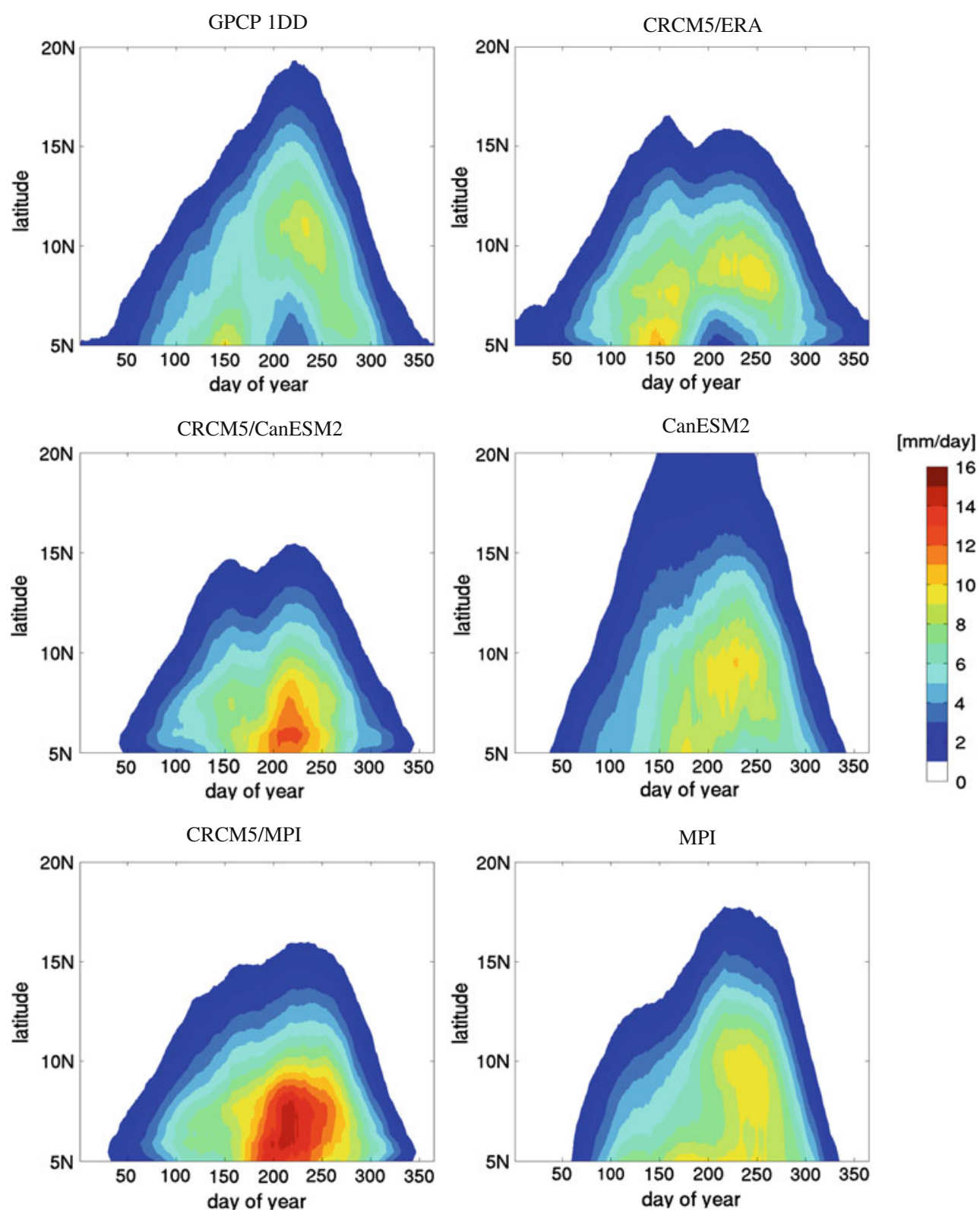

Fig. 9 Mean (1997-2008) annual cycle of precipitation (mm/day) over West Africa from GPCP 1DD dataset (top left) and CRCM5/ ERA (top right), as well as CRCM5/CanESM2 and CRCM5/MPI

(left), and the driver models CanESM2 and MPI (right), averaged over $10^{\circ} \mathrm{W}-10^{\circ} \mathrm{E}$. A 31 -day moving average has been applied to remove high-frequency variability

driven but also in the CanESM2- and MPI-driven simulations. This feature seems particular to CRCM5 and is in accordance with the dry bias in the Sahel region (Figs. 5b, $6 a, 9)$ as discussed in HD12. The intensity and the shape of the TEJ are better represented in both CRCM5 simulations than in the driver models.

\section{Climate-change projections}

The projected changes in mean 2-m temperature from CRCM5 simulations driven by CanESM2 and MPI, as well

as from the corresponding driving models, are shown in Fig. 11, for JFM (Fig. 11a) and JAS (Fig. 11b), for three future time slices: (2011-2040), (2041-2070) and (2071-2100), compared to the reference period (1981-2010). In both seasons, all models become progressively warmer as the end of the twenty-first century approaches, the JAS season being generally warmer than JFM. There are some notable differences between models. CanESM2 projected warming is substantially larger than that of MPI, and the CRCM5 projected warming is always smaller than that of its driving GCM. The CanESM2-driven CRCM5 projected warming pattern is rather different 

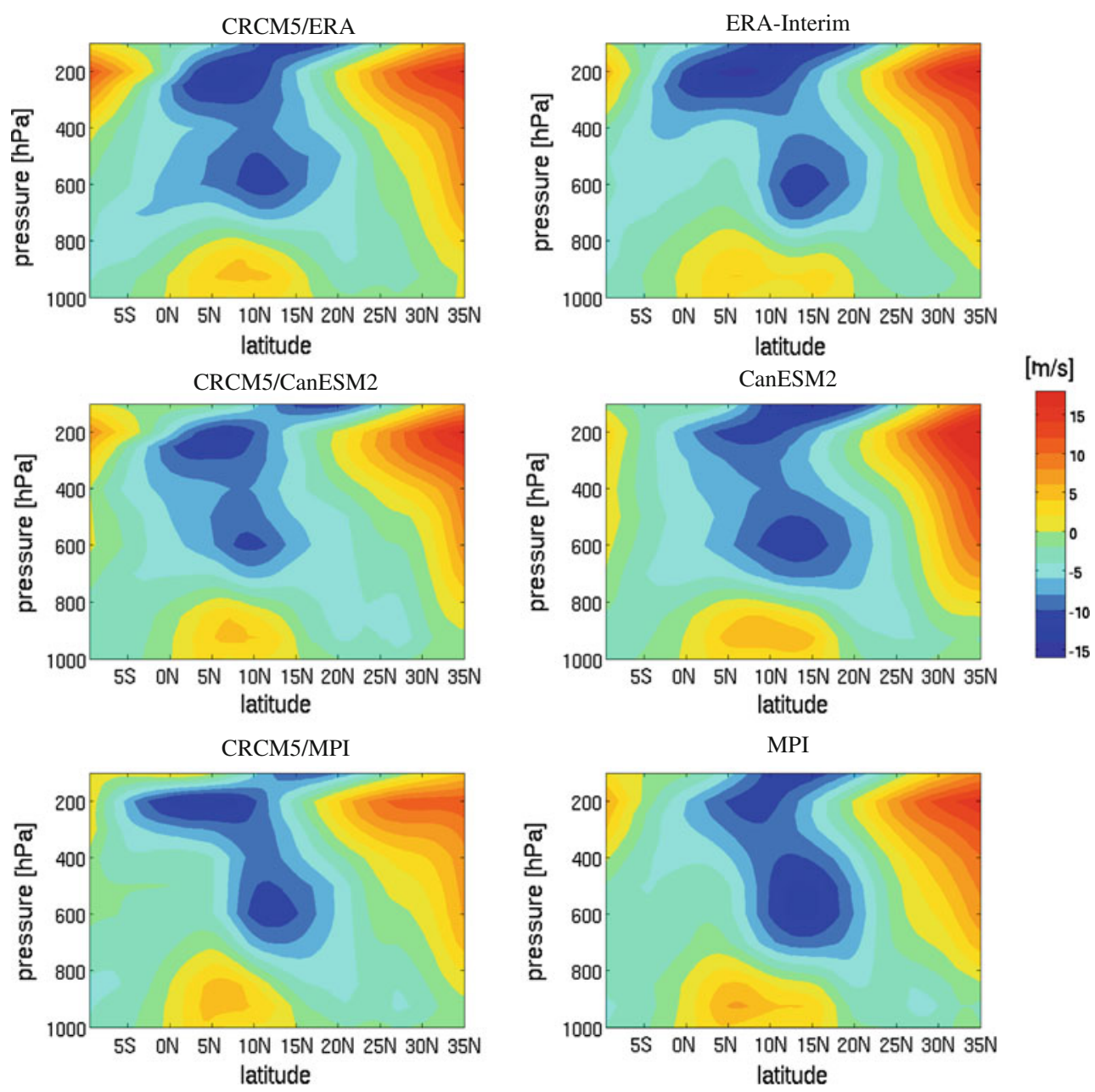

Fig. 10 Mean (1989-2008) vertical cross-section of zonal wind averaged between $10^{\circ} \mathrm{W}$ and $10^{\circ} \mathrm{E}$, from CRCM5/ERA (top left), CRCM5/CanESM2 (middle left), CRCM5/MPI (bottom left), as well

from that of CanESM2, particularly in JFM. In this season CanESM2 shows three regions of maximum warming that get more intense towards the end of the twenty-first century: a portion of West Africa, the Congo Basin and the Kalahari and Namibia deserts in South Africa. At the same time, the CanESM2-driven CRCM5 only shares the first two regions of maximum warming, with less intensity and over a smaller area. CRCM5 also shows a maximum of warming over Ethiopia and the Horn of Africa that is not so well defined in CanESM2. On the other hand, when driven by MPI the CRCM5 shows more similar warming intensities with respect to the driving model, and these are smaller than those projected by CanESM2 and CanESM2driven CRCM5. Although the warming pattern of MPIdriven CRCM5 and MPI is not identical, both share a region of warming in South Africa which is however of greater intensity and extension in MPI.

In JAS, there is a generalised warming shared by all models, but little consensus for the magnitude and location

as from the corresponding driving data: ERA-Interim (top right), CanESM2 (middle right) and MPI (bottom right)

of the regions of maximum warming. The CanESM2 projects a maximum warming in an almost latitudinal band north of $15^{\circ} \mathrm{N}$ over the whole continent; this pattern is more or less reproduced by CRCM5, but with less intensity. The MPI on the other hand shows a maximum warming over part of the Sahara only and in the Sahel region in a latitudinal band centred at $15^{\circ} \mathrm{N}$; this pattern is reproduced only in part by the CRCM5, which shares only the Sahel warming with its driving model. Maximum warming south of the equator from the middle of the century and towards the end is present in both GCMs, although very much less intense in MPI; it is also present in the CanESM2-driven CRCM5, not in the MPI-driven CRCM5. In general, the magnitude of projected warming is larger in CanESM2 than in MPI, and the same is true for the corresponding GCM-driven CRCM5 simulations.

Corresponding projected precipitation changes are shown in Fig. 12. In JFM (Fig. 12a) projected changes are overall small and there is little consensus between models. 
(a) JFM

(2011-2040) - (1981-2010)
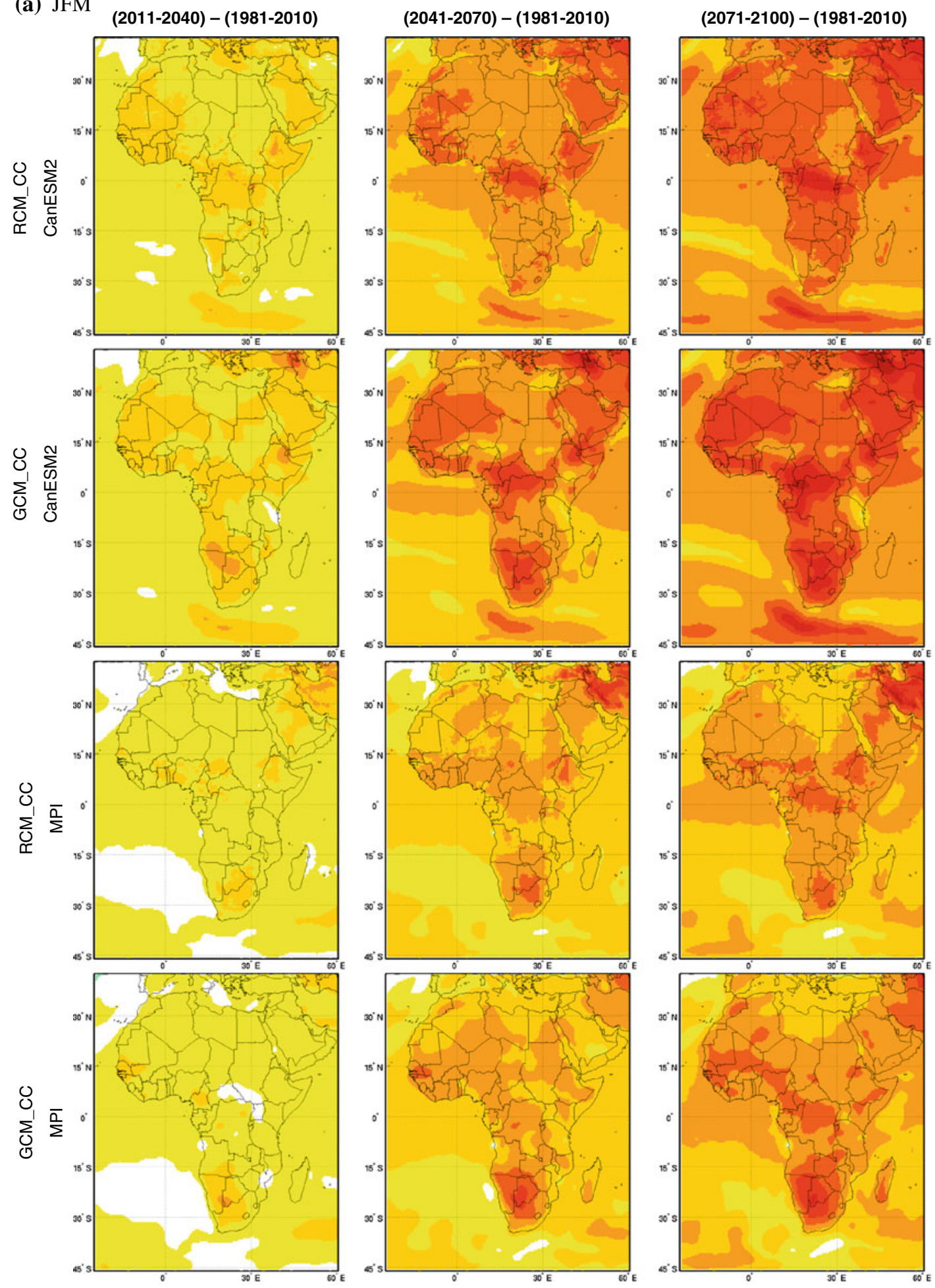

Fig. 11 Projected changes in seasonal-mean 2-m temperature for a JFM and b JAS from CRCM5 driven by CanESM2 (line 1) and by 2 and 4). Left (2011-2040)-(1981-2010), middle (2041-2070)(1981-2010), and right (2071-2100)-(1981-2010)

MPI (line 3), as well as from the corresponding driving models (lines

CanESM2 gives an increase in precipitation in the East Africa region that intensifies towards the end of the century, which is not the case for MPI or CanESM2-driven
CRCM5 simulations. CanESM2-driven CRCM5 simulation projects drying in the Congo basin while CanESM2 projects no change in the region. MPI and MPI-driven 
(b) JAS
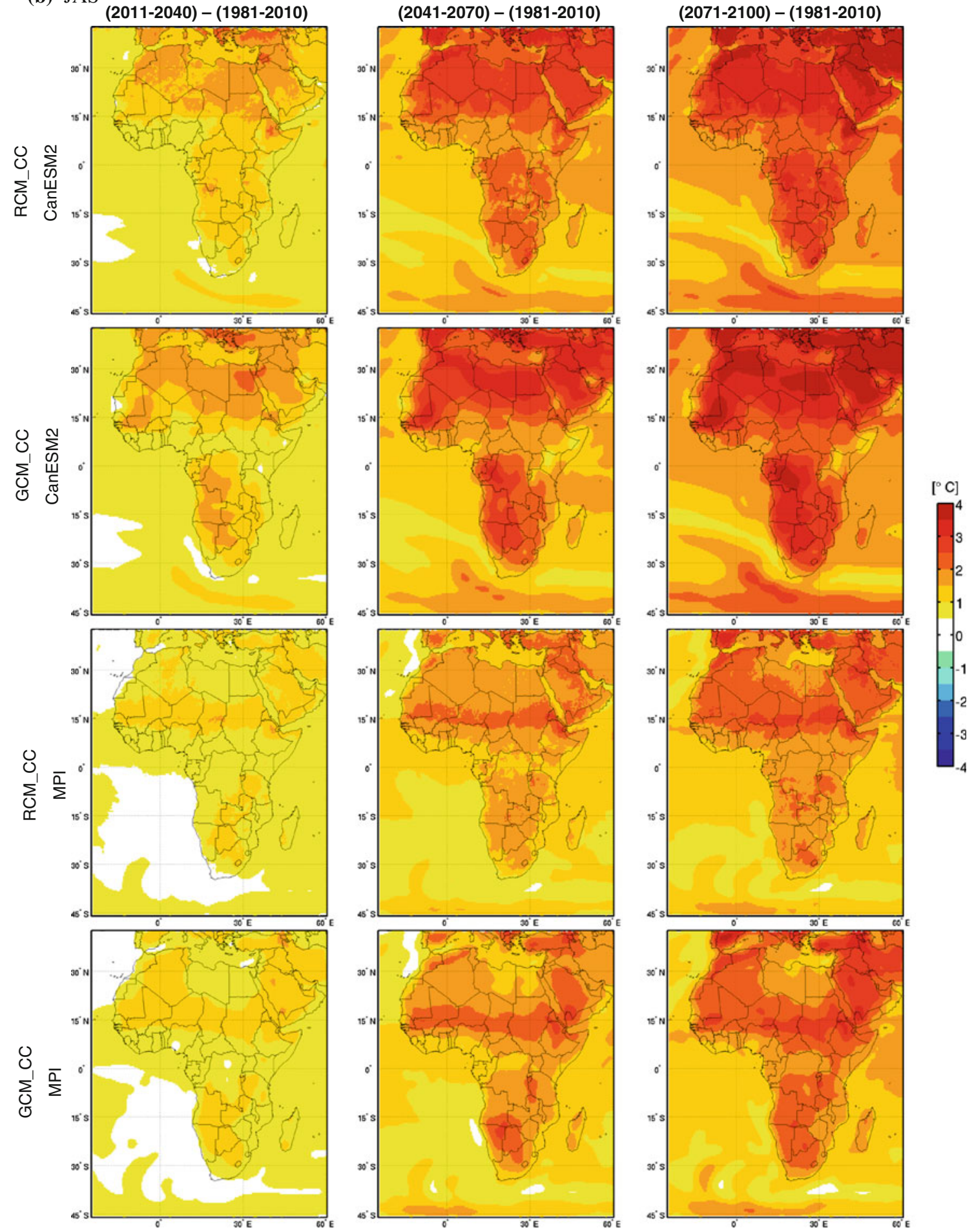

Fig. 11 continued

CRCM5 simulations project little change in precipitation over land. Otherwise over the ocean there is an increase in precipitation over the equatorial Atlantic Ocean growing toward the end of the century in MPI, which is not reproduced in the MPI-driven CRCM5 simulation. At the same time, to the south, there is a reduction in precipitation in a band centred at $15^{\circ} \mathrm{S}$ which is also reproduced in the MPIdriven CRCM5.

The common feature of the projected precipitation changes in JAS (Fig. 12b) is a narrowing of the tropical 
(a) JFM
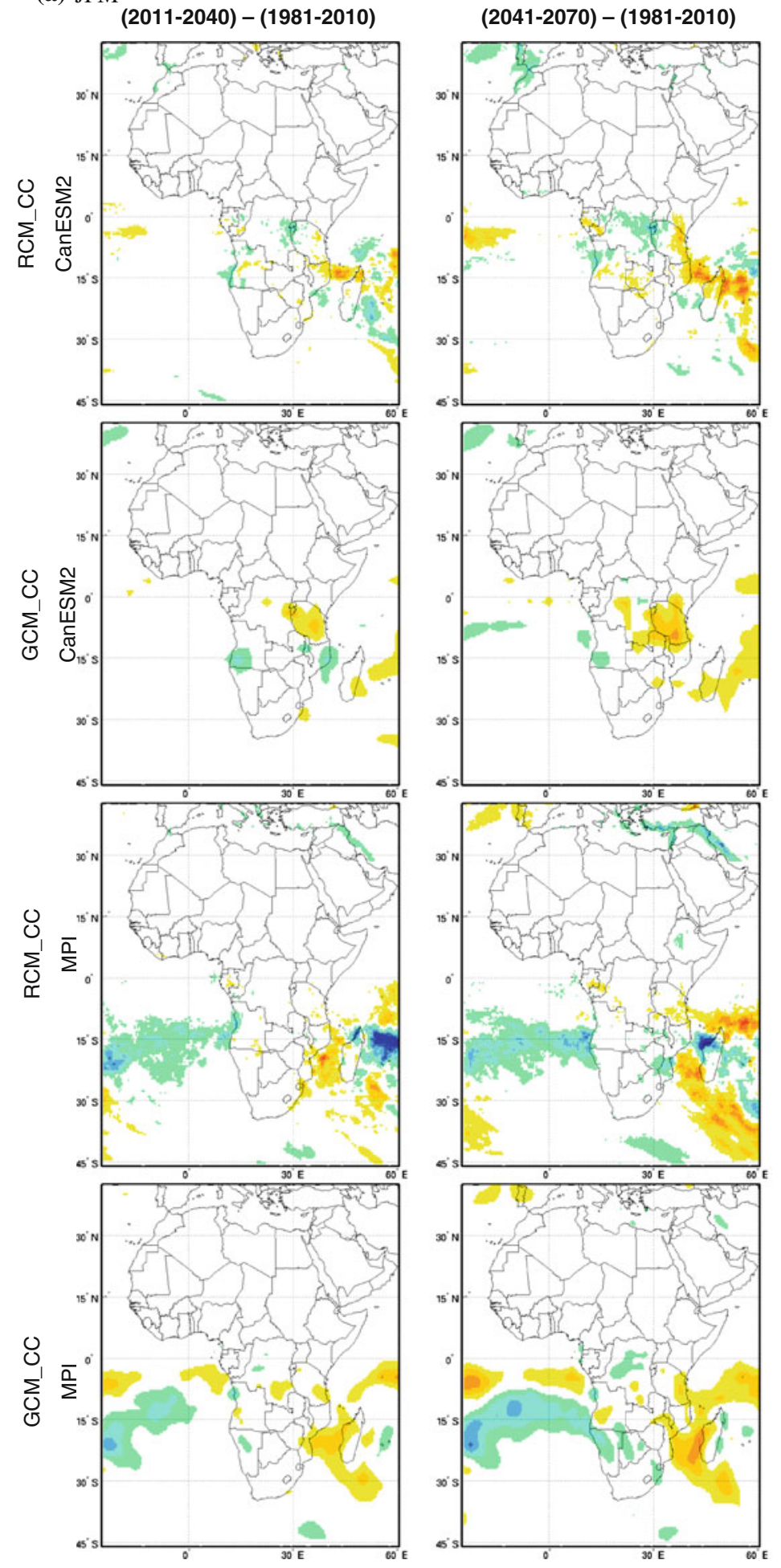

Fig. 12 Projected changes in seasonal-mean precipitation for a JFM and b JAS from CRCM5 driven by CanESM2 (line 1) and by MPI (line 3), as well as from the corresponding driving models

rainbelt and intensification of its maximum, although the details of projected changes differ among the models. There is a decrease in precipitation over the equatorial (lines 2 and 4). Left (2011-2040)-(1981-2010), middle (2041-2070)(1981-2010), and right (2071-2100)-(1981-2010)

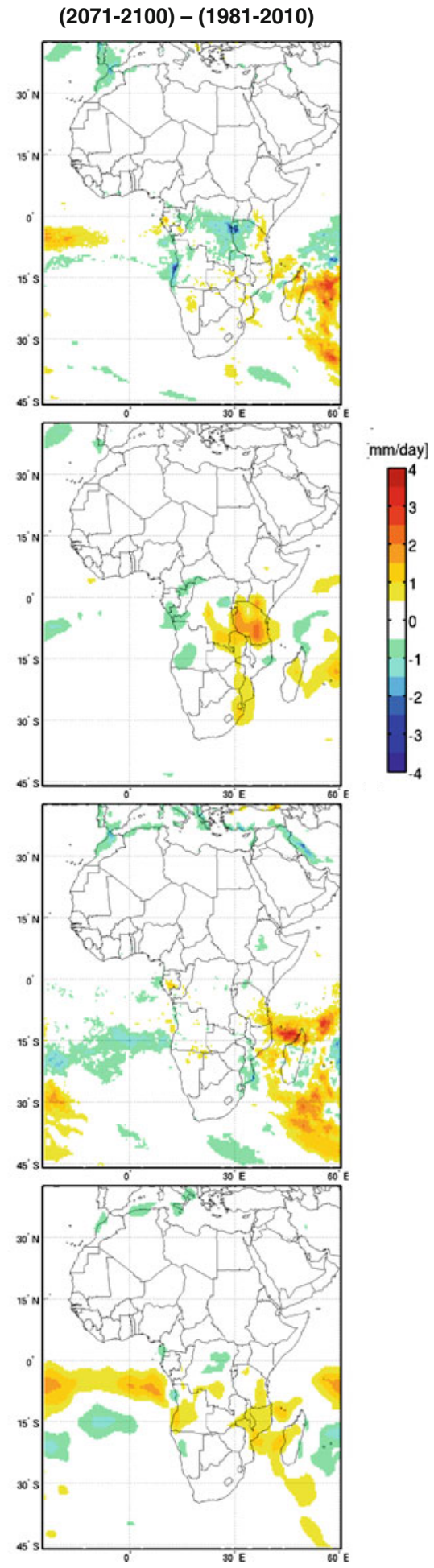

Atlantic Ocean and the Gulf of Guinea in CanESM2, particularly intense in the second half of the twenty-first century, and it goes inland over central Africa to the east 
(b) JAS (2011-2040)-(1981-2010)
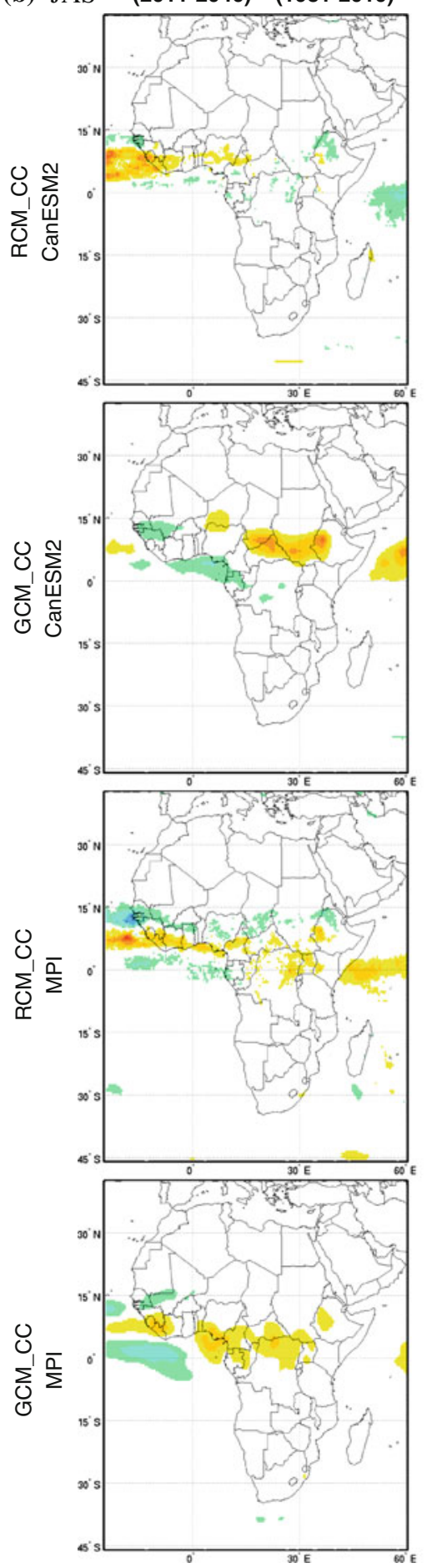
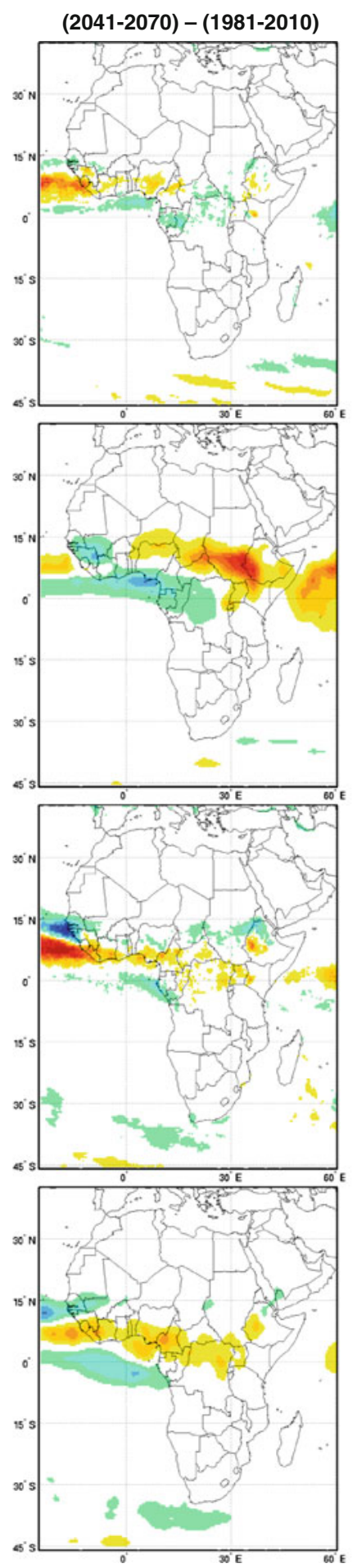

(2071-2100) - (1981-2010)
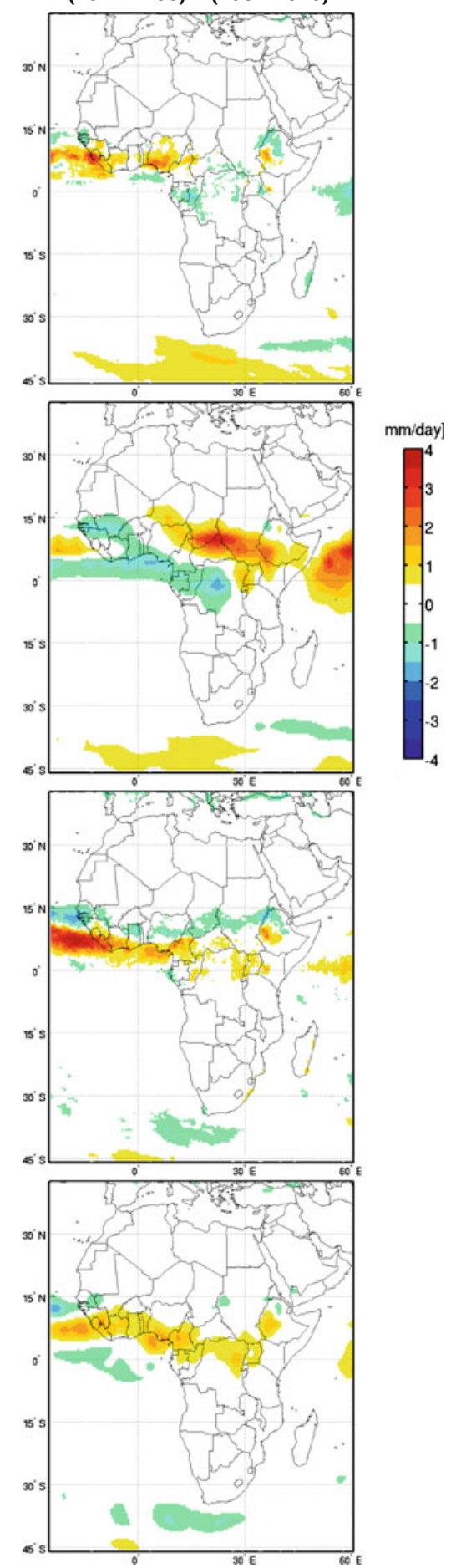

Fig. 12 continued

and over southern Mali and Senegal to the north. At the same time there is an intensification of the precipitation over land in a band south of $15^{\circ} \mathrm{N}$. Drying is also projected but of lesser extent by MPI over the ocean to the north and to the south of the tropical rainbelt for which there is a projected increase of intensity. All GCM-driven CRCM5 simulations project continuous drying over the Sahel during the twenty-first century, stronger in the MPI-driven simulation. The pattern of precipitation changes over West Africa projected for the end of the century by the MPIdriven CRCM5 is in fact quite similar to that obtained by Sylla et al. (2010) with RegCM3 driven by an earlier 

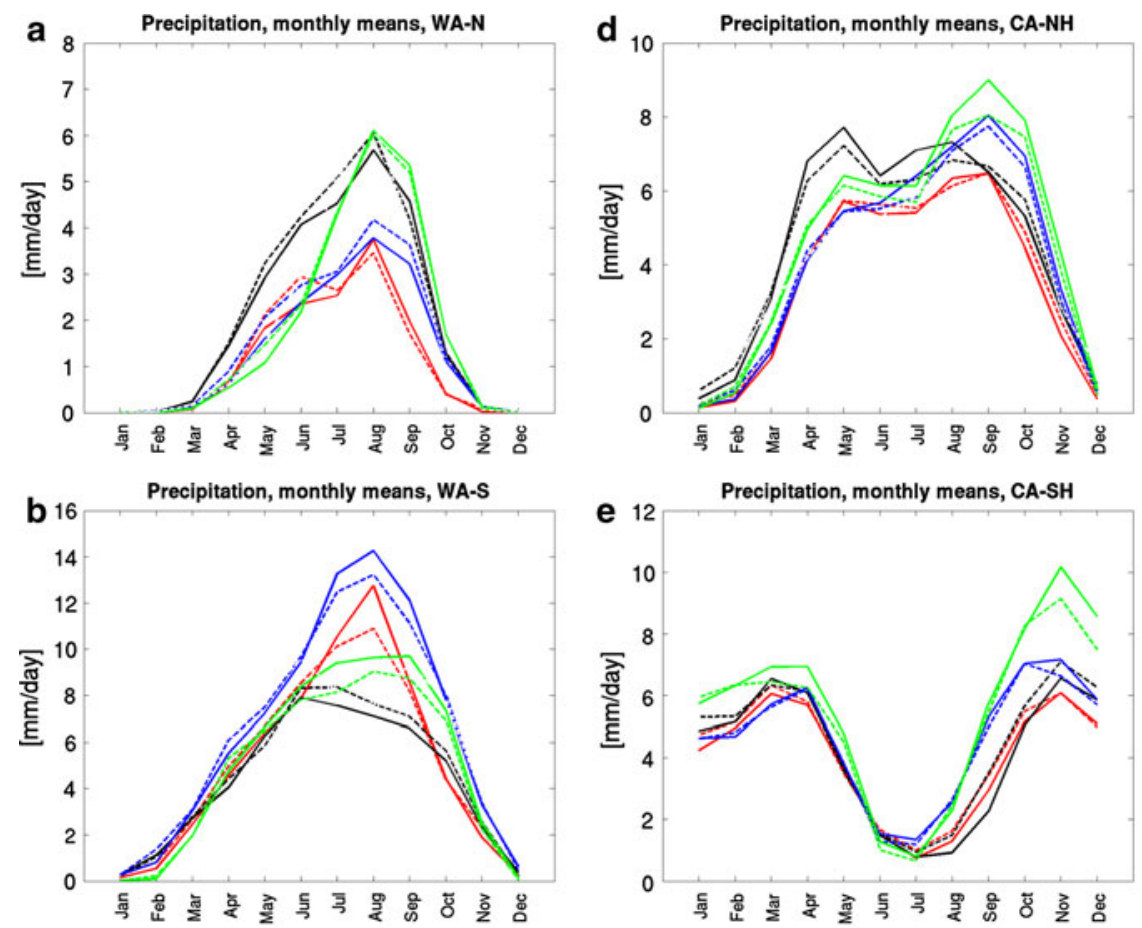

- CRCM_CanESM2_2071-2100

CanESM2_2071-2100

-.-.CanESM2_1981-2010

- CRCM_MPI-ESM_2071-2100

----CRCM_MPI-ESM_1981-2010

MPI-ESM_2071-2100

MPI-ESM_1981-2010
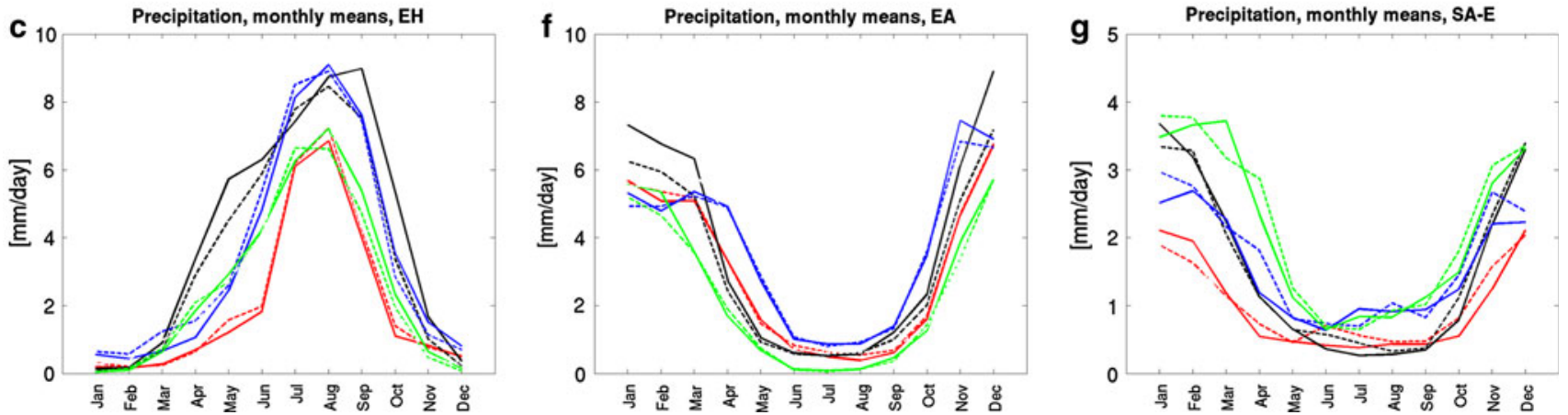

Fig. 13 Projected mean annual cycle of precipitation $(\mathrm{mm} /$ day) from CRCM5/CanESM2 (red), CanESM2 (black), CRCM5/MPI (blue), MPI (green), for regions of the African CORDEX domain: a West Africa-North (WA-N), b West Africa-South (WA-S), c Ethiopian

Highlands (EH), d Central Africa-Northern Hemisphere (CA-NH), e Central Africa-Southern Hemisphere (CA-SH), f East Africa (EA), g South Africa-East (SA-E). Dashed lines represent the reference period (1981-2010) and solid lines the future time slice (2071-2100)

version of MPI CGCM under the A1B scenario. All the models, including the two GCM-driven CRCM5 simulations, project an increase in precipitation over the ocean in the West Coast although with different intensities, the largest ones are found in both CRCM5 simulations.

The projections for the annual cycle of precipitation for the last 30 years of the twenty-first century are shown in Fig. 13 (for the same regions of Fig. 6) as obtained from the CanESM2- and MPI-driven CRCM5 simulations, as well as from CanESM2 and MPI themselves. Solid lines represent the future time slice (2071-2100) and dashed lines the reference period (1981-2010); since the pattern is essentially the same for the 3 future time slices, we choose to show only the last one. Generally, for each model there are no major changes between the simulated annual cycles in current and future climate, although there are some differences. As shown before (Fig. 6a) in the WA-N region both GCMs have higher intensities than the corresponding GCM-driven CRCM5 simulations (Fig. 13a) for the unique rainy season of the region, with CanESM2 giving the largest rainy season. Before the rainfall peak of August, there is a slight projected reduction in precipitation by CanESM2 and CanESM2-driven CRCM5. In the other regions with only one rainy season (EA, SA-E) all the models show little change in the future compared to the current climate, with the exception of CanESM2 that projects higher intensities in JFM for the EA region (Fig. 13f). This is also the case in the Ethiopian Highlands (EH) where again CanESM2 projects not only higher intensities but also a longer rainy season, while CanESM2-driven 
CRCM5 remains very close to the current climate situation and shows the narrowest rainy season in both time slices (Fig. 13c). On the contrary, MPI and MPI-driven CRCM5 share almost the same shape for the annual cycle, but CRCM5 gives higher intensities than the MPI in both time slices. In the equatorial regions, the double rainy season persists for the CA-NH (Fig. 13d) and CA-SH (Fig. 13e) regions, with an intensification projected by MPI in both seasons and for both regions, and by CanESM2 in both seasons but only for the CA-NH region. MPI-driven CRCM5 also projects a slight intensification but only for the second rainy season in both regions. As shown before (Fig. 6b) the double rainy season of the Guinea Coast region (WA-S), properly reproduced by CRCM5 when driven by ERA, disappears when driven by either CanESM2 or MPI models that also show only one long rainy season. Fig. 13b shows that while CanESM2 projects a slight reduction of the intensity of precipitation, MPI projects an intensification, as well as MPI- and CanESM2driven CRCM5 simulations, both of which are already of higher intensities in both time slices than their respective driving models.

As regards of the simulated diurnal cycle and daily precipitation intensity distributions, there are no significant changes in the projections by all of the models compared to the current climate.

Figure 14 shows time-latitude Hovmöller diagrams of daily precipitation ( $\mathrm{mm} /$ day) in West Africa as projected by the models for three future time slices and for the current climate period (1981-2010). We saw before in Fig. 9 that in the region of the WAM the ERA-driven CRCM5 was capable of reproducing the two rainy seasons of the Guinea Coast $\left(5^{\circ} \mathrm{N}\right)$ : the first one in May-June and the second one in September-October, as well as the rainy season of the Sahel in JAS. The double rainy season of the Guinea Coast is lost when CRCM5 was driven by either GCM (CanESM2 and MPI models) that also missed this pattern. This is confirmed in Fig. 14 (top rows) for the 30 -years period of current climate. As time passes, the shape and main features for each model remain quite similar, except for variations in the intensity of simulated precipitation from one model to the other and from one time slice to the other. Thus, for the period (2041-2070) CanESM2 projects a slight intensification of the precipitation around its maximum at $10^{\circ} \mathrm{N}$ (Fig. 14a), while for the following 30-years period there is a projected reduction to values under the maximum of current climate (1981-2010). CanESM2-driven CRCM5 on the contrary projects a continuous intensification of precipitation until the end of the twenty-first century. On the other hand, the MPI-driven CRCM5 projects also an increase of the precipitation intensities as time passes, while its driver MPI model projects a gradual intensification essentially from the middle of the twenty-first century and until the end (Fig. 14b). This being said, it is difficult to give credibility to the projections of models that failed to properly represent the current climate. This is particularly true in the WAM region for which the CRCM5, due to the bad boundary conditions coming from the driver models, simulates a very different mean annual cycle of precipitation compared to those obtained when driven by the reanalyses (see Fig. 9, top right). CanESM2 and MPI, although suffering from the misrepresentation of the seasonal migration of WAM precipitation in the region of the Guinea Coast, show maximum intensities around $10^{\circ} \mathrm{N}$ that are more in accordance with the observations, but probably not for the right reason given the large differences noted in discussing the DPID.

Similarly, the circulation in the region of the WAM as projected by all of the models show little changes, as can be seen in Fig. 15. The only remarkable changes are an intensification of the monsoonal winds by CanESM2 (Fig. 15a) in the second half of the century, which is not reproduced by the CRCM5, and a weakening of the TEJ by MPI in the next 30 years (2011-2040) to almost an extinction in the following period (2041-2070) and a come back to values near the current climate at the end of the century. The MPI-driven CRCM5 seems not to be affected at all by these variations of the driving model.

\section{Conclusions}

In this paper, as part of our contribution to the CORDEX project, we analysed the performance of the fifth-generation Canadian Regional Climate Model (CRCM5) in simulating current climate over Africa when driven by two different coupled GCMs: the Earth system version of the Canadian Centre for Climate Modelling and Analysis (CanESM2) and the Earth system version of the MaxPlanck-Institut für Meteorologie (MPI-ESM-LR), and we presented the climate-change projections from the CanESM2-driven and MPI-driven CRCM5 simulations for the twenty-first century under the RCP4.5 emission scenario.

The two GCM-driven CRCM5 simulations of current climate were compared to different observational datasets, as well as to a reanalyses-driven CRCM5 simulation that was analysed in Hernández-Díaz et al. (2012). The performances of the CRCM5 simulations were analysed with regard of the seasonal means of temperature and precipitation, the annual and diurnal cycle of precipitation, the daily precipitation intensity distributions and the representation of the WAM. Biases in temperature and precipitation differ in sign, magnitude and patterns between different models. As expected, the CRCM5 biases are smaller than those of the two driving GCMs for the 2-m 
Fig. 14 Simulated mean annual cycle of precipitation ( $\mathrm{mm} /$ day) over West Africa, averaged over $10^{\circ} \mathrm{W}-10^{\circ} \mathrm{E}$, for the periods (1981-2010), (2011-2040), (2041-2070) and (2071-2100). Left column is for GCM-driven CRCM5 and right column is for corresponding driving GCM; a CRCM5/CanESM2 and CanESM2, and b CRCM5/MPI and MPI. A 31-day moving average has been applied to remove high-frequency variability (a)
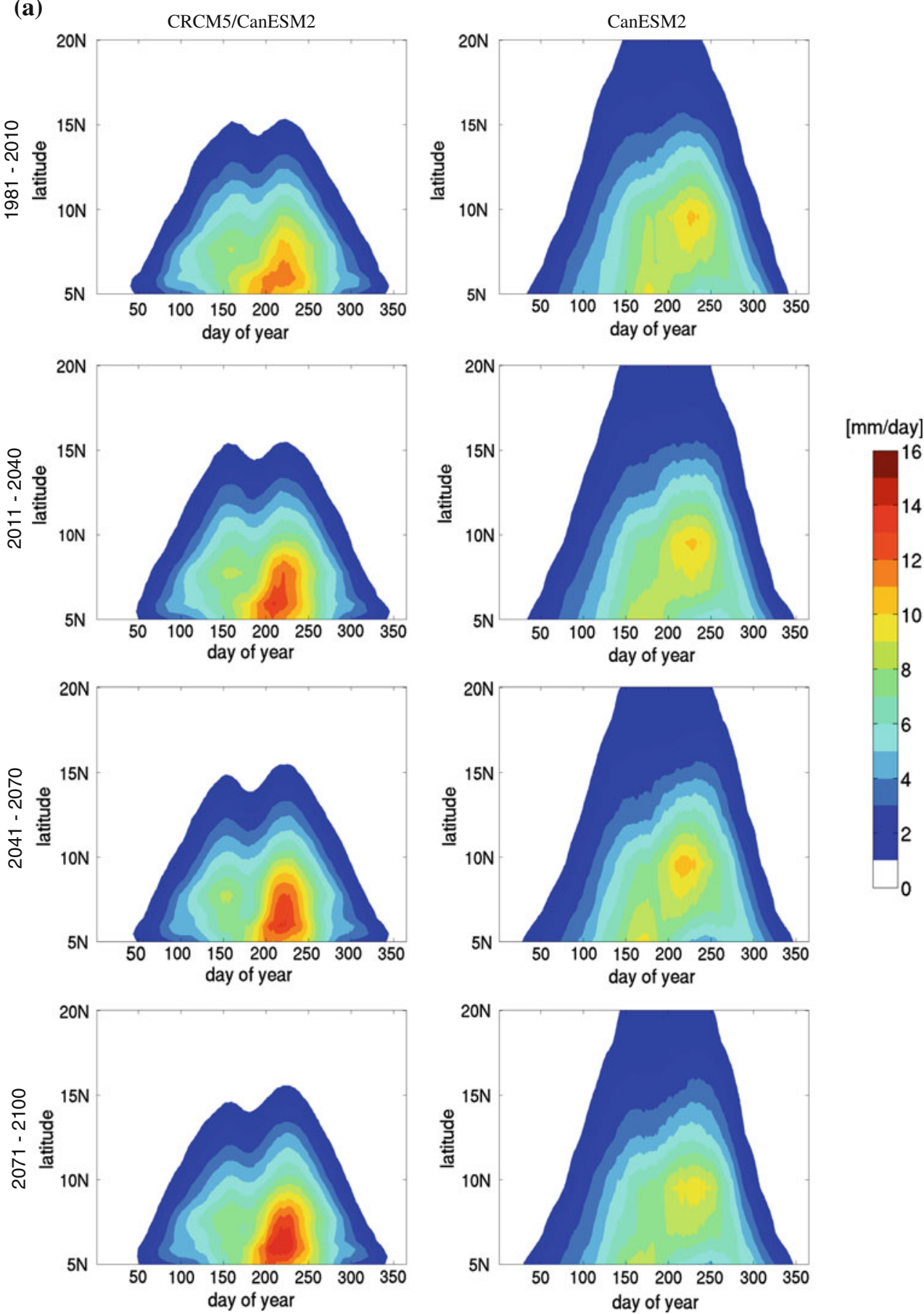

temperature field in general, and this is also valid for precipitation, although to a lesser extent. The GCMs warm biases for 2-m temperature in current climate are overall corrected by the CRCM5, which constitutes an added value resulting from dynamical downscaling. On the other hand, some cold biases such as in the elevated terrains of Ethiopia and Sudan, present in the ERA-driven CRCM5 simulation in JAS, remain when driven by the GCMs and are somehow amplified in the case of the MPI-driven simulation although not present in the driving model. In JFM the tropical rainbelt is improved in CRCM5 compared to the driving GCMs, but on the other hand the wet bias east of Madagascar is intensified. In JAS, the wet bias of MPI in the Guinea Gulf and its dry bias in South Sudan are reduced in the MPI-driven CRCM5 simulation. The wet bias over the ocean in the Gulf of Guinea, present also in CanESM2, propagates to the coast in both GCM-driven simulations. This wet bias is associated with the GCM- 

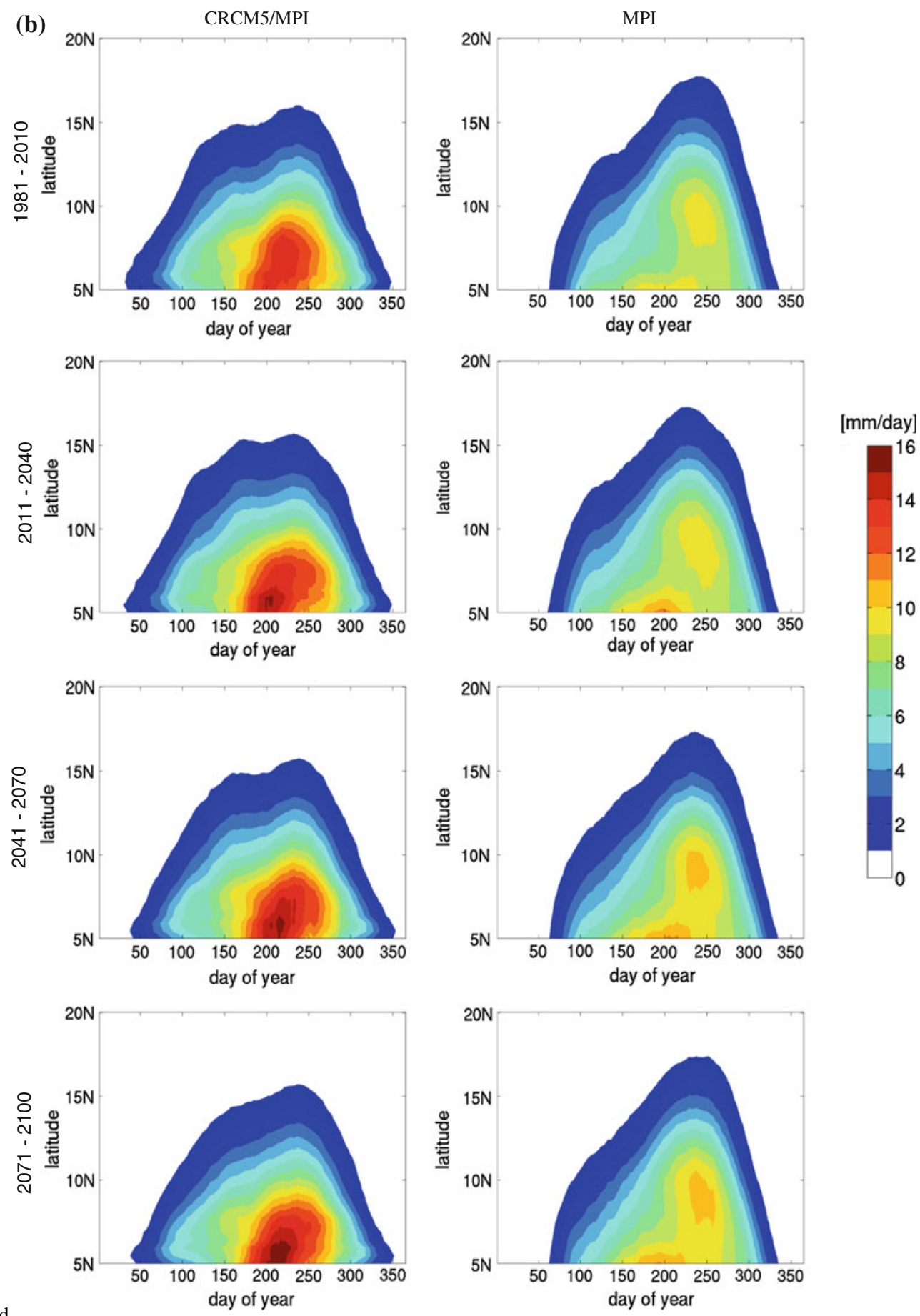

Fig. 14 continued

simulated SSTs biases. In general, the CRCM5 simulations improve upon many of the driving GCMs features, including the annual cycle of precipitation and the distribution of daily precipitation intensities. In particular CRCM5 was able to correct the systematic bias of CanESM2 DPID toward lower precipitation intensities and its tendency for bimodal precipitation distribution. But in the region of the WAM, as a result of the GCM-simulated SST biases, the GCM-driven CRCM5 simulated annual

cycle of precipitation misses the double rainy season of the Guinea Coast. This reinforces the point that although highresolution nested RCM are capable of improving upon many aspects of coarse-resolution driving data, there is a limit to what can be corrected by the downscaling of imperfect driving conditions.

All projected climates become progressively warmer as the end of the twenty-first century approaches, the JAS season being generally warmer than JFM, but there are 
(a)
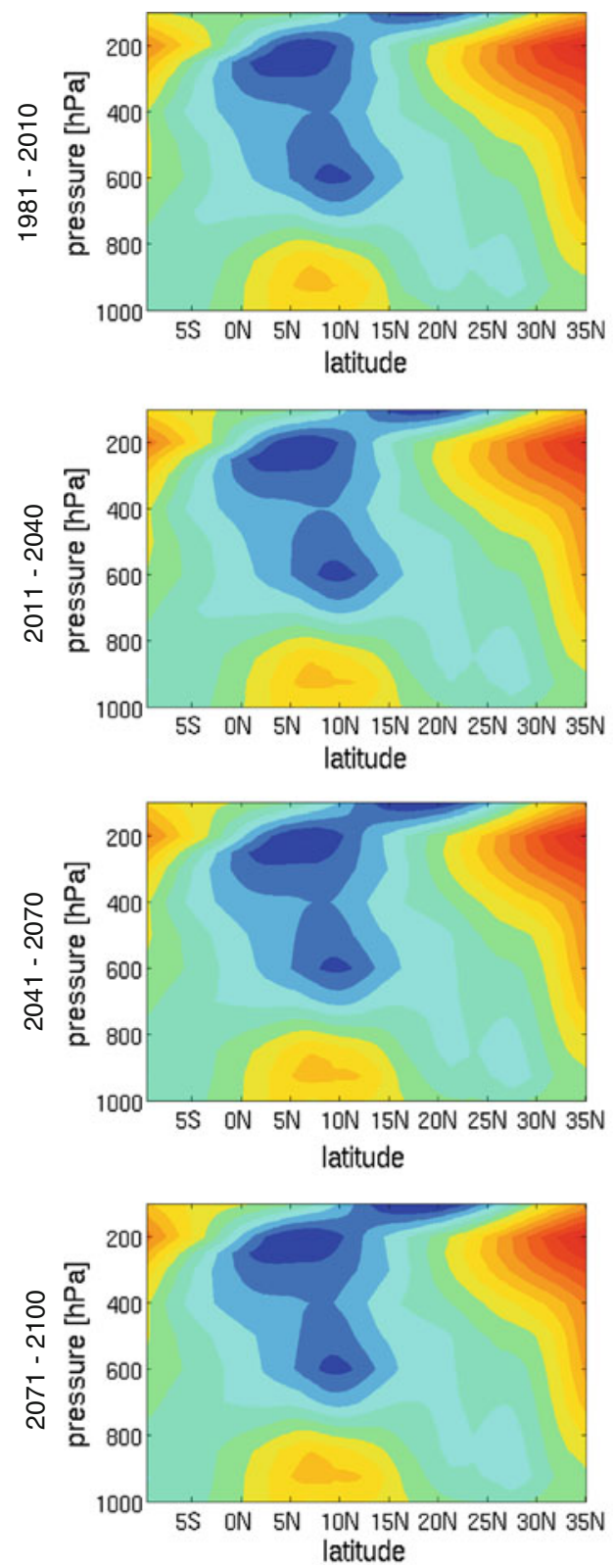

Fig. 15 Simulated vertical cross-section of JAS mean zonal wind $(\mathrm{m} / \mathrm{s})$ over West Africa, averaged over $10^{\circ} \mathrm{W}-10^{\circ} \mathrm{E}$, for the periods (1981-2010), (2011-2040), (2041-2070) and (2071-2100). Left

some notable differences between models. CanESM2 projected warming is substantially larger that of MPI, and the CRCM5 projected warming is always smaller than that of its driving GCM. The projected warming is shared by all of the models, but there is little consensus for the magnitude and location of the regions of maximum warming. Nonetheless, when driven by MPI the CRCM5 shows more similar warming intensities with respect to the driving model than when driven by CanESM2.
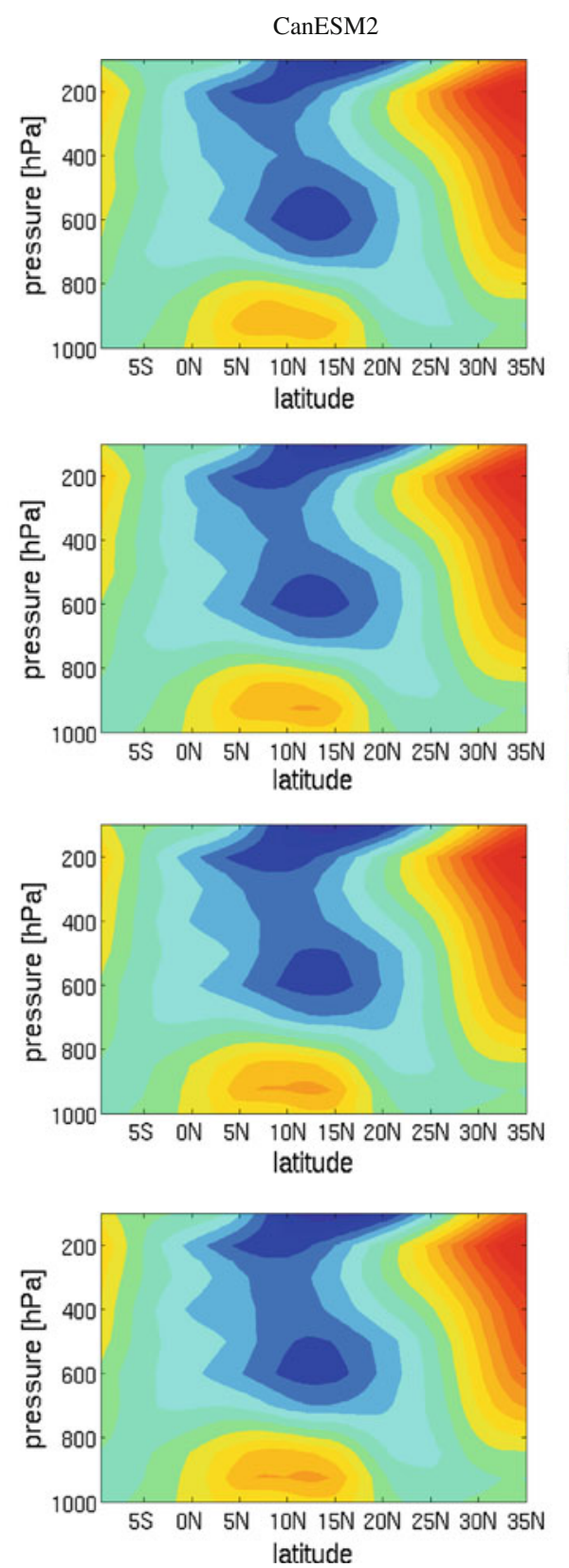

column is for GCM-driven CRCM5 and right column is for corresponding driving GCM; a CRCM5/CanESM2 and CanESM2, and $\mathbf{b}$ CRCM5/MPI and MPI

Projected changes of precipitation in JFM are overall small but there is little consensus between the models projections and between the CRCM5 and its driving models, casting some doubt whether these are statistically significant. In JAS, the common feature of the projected precipitation changes is a narrowing of the tropical rainbelt and an intensification of its maximum, although the details of projected changes differ among the models. There are no major changes between the simulated annual cycles in 

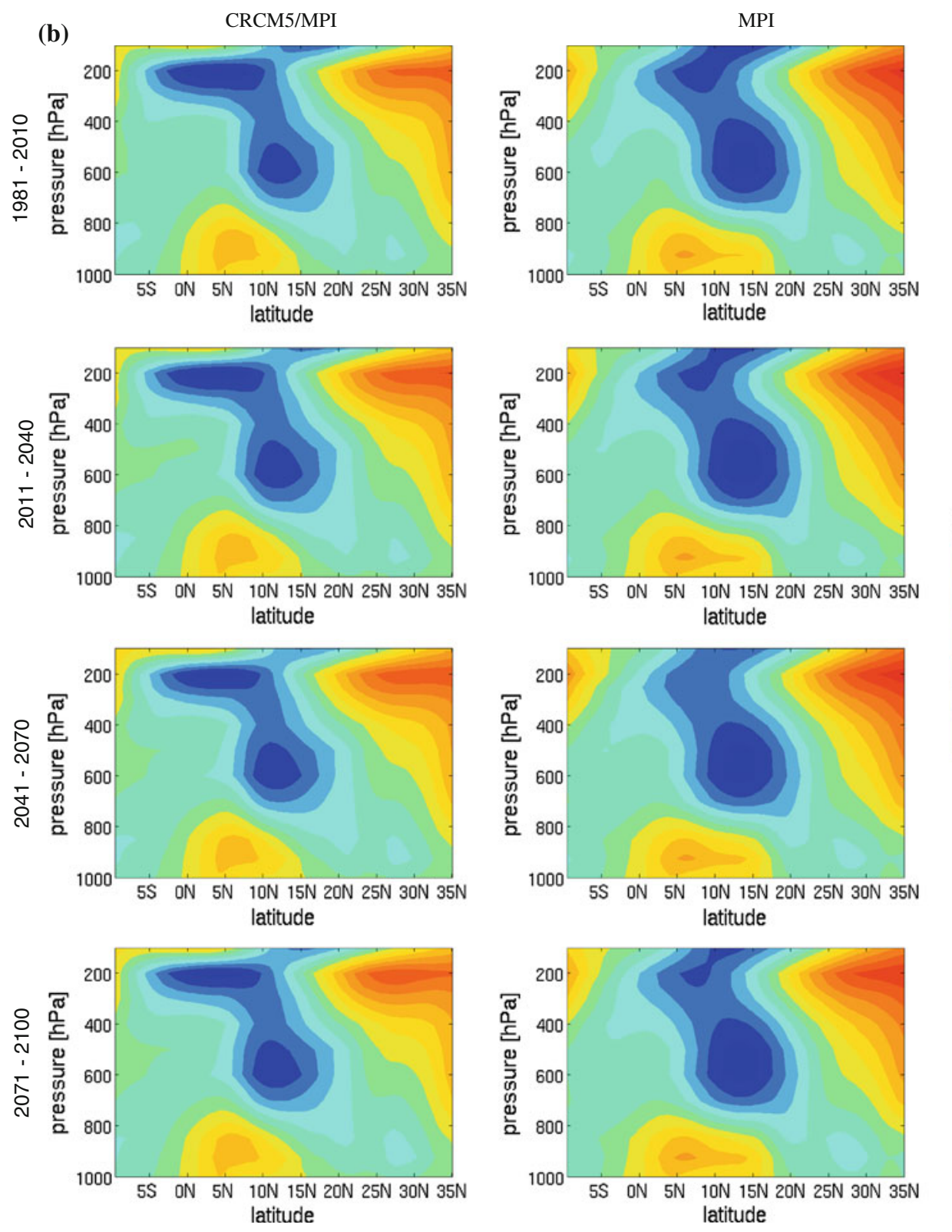

Fig. 15 continued

current and future climate, although there are some differences. In the equatorial regions (CA-NH, CA-SH and WA-S), all models but CanESM2 project an intensification of the precipitation during the rainy seasons. On the contrary, CanESM2 projects decreased precipitation, in particular for the WA-S and CA-NH regions. For the other regions CanESM2 projects a longer rainy season for the EH region and higher intensities for EA region, while a slight reduction of intensities are projected for the Sahel region (WA-N) by CanESM2 and MPI-driven CRCM5. With regards to the simulated diurnal cycle and daily precipitation intensity distributions, there are no significant changes in the projections by all of the models compared to the current climate.

Both GCM-driven CRCM5 simulations as well as the GCMs project an intensification of the tropical rainbelt in the region of the WAM to varying degrees. It is important however to keep in mind the difficulties that models encountered in simulating the WAM features in the current climate; so their future climate projections in this respect must be considered with caution.

Acknowledgments This research was funded by the Canadian Foundation for Climate and Atmospheric Sciences (CFCAS), the Québec's Ministère du Développement Économique, Innovation et 
Exportation (MDEIE), the Natural Sciences and Engineering Research Council of Canada (NSERC), Hydro-Québec, the Ouranos Consortium on Regional Climatology and Adaptation to Climate Change, the Mathematics of Information Technology and Complex Systems (MITACS) Network of Centres of Excellence, and the Canada Research Chairs programme. The calculations were made possible through the CLUMEQ Consortium, on the Colosse and Guillimin high-performance computing platforms; CLUMEQ is part of the Compute Canada national HPC platform and a member of the Calcul Québec regional HPC platform. The authors thank Mr. Georges Huard and Mrs. Nadjet Labassi for maintaining an efficient and user-friendly local computing facility. The authors are also grateful to the following collaborators at Environment Canada: $\mathrm{Mr}$. Michel Desgagné for his work in developing a nested version of GEM, Dr. Diana Verseghy for allowing to use the code of CLASS 3.5, Mr. Richard Harvey for helping with CLASS, and specially Dr. Bernard Dugas for his unwavering support on developing CRCM5 since the beginning of this work more than a decade ago. This study would not have been possible without the access to valuable data from ERA-Interim, CRU, UDEL, GPCP and TRMM, as well as the outputs from CanESM2 and MPI-ESM-LR models through the CMIP5 database.

Open Access This article is distributed under the terms of the Creative Commons Attribution License which permits any use, distribution, and reproduction in any medium, provided the original author(s) and the source are credited.

\section{References}

Adler RF et al (2003) The version-2 Global Precipitation Climatology Project (GPCP) monthly precipitation analysis (1979-present). J Hydrometeorol 4:1147-1167

Bélair S, Mailhot J, Girard C, Vaillancourt P (2005) Boundary-layer and shallow cumulus clouds in a medium-range forecast of a large-scale weather system. Mon Weather Rev 133:1938-1960

Benoit R, Côté J, Mailhot J (1989) Inclusion of a TKE boundary layer parameterization in the Canadian regional finite-element model. Mon Weather Rev 117:1726-1750

Boone A, de Rosnay P, Basalmo G, Beljaars A, Chopin F, Decharme B, Delire C, Ducharne A, Gascoin S, Grippa M, Guichard F, Gusev Y, Harris P, Jarlan L, Kergoat L, Mougin E, Nasonova O, Norgaard A, Orgeval T, Ottlé C, Poccard-Leclercq I, Polcher J, Sandholt I, Saux-Picart S, Taylor C, Xue Y (2009) The AMMA land surface model intercomparison project. Bull Am Meteorol Soc 90:1865-1880. doi:10.1175/2009BAMS2786.1

Burpee RW (1972) The origin and structure of easterly waves in the lower troposphere of North Africa. J Atmos Sci 29:77-90

Cook KH (1999) Generation of the African easterly jet and its role in determining West African precipitation. J Clim 12:1165-1184

Cook KH, Vizy EK (2006) Coupled model simulations of the West African monsoon system: twentieth-century simulations and twenty-first-century predictions. J Clim 19:3681-3703

Delage Y (1997) Parameterising sub-grid scale vertical transport in atmospheric models under statically stable conditions. Bound Layer Meteorol 82:23-48

Delage Y, Girard C (1992) Stability functions correct at the free convection limit and consistent for both the surface and Ekman layers. Bound Layer Meteorol 58:19-31

Di Luca A, de Elía R, Laprise R (2012) Potential for added value in precipitation simulated by high-resolution nested regional climate models and observations. Clim Dyn. doi:10.1007/ s00382-011-1068-3
Druyan LM (2010) Studies of the 21st century precipitation trends over West Africa. Int J Climatol 31:1415-1572. doi:10.1002/ joc. 2180

Druyan LM, Feng J, Cook KH, Xue Y, Fulakeza M, Hagos SM, Konaré A, Moufama-Okia W, Powell DP, Vizy EK, Ibrah SS (2010) The WAMME regional model intercomparison study. Clim Dyn 35:175-192. doi:10.1007/s00382-009-0676-7

Feser F, Rockel B, von Storch H, Winterfeldt J, Zahn M (2011) Regional climate models add value to global model data. Bull Am Meteorol Soc 92:181-1192. doi:10.1175/2011BAMS3061.1

Giorgi F, Jones C, Asrar G (2009) Addressing climate information needs at the regional level: the CORDEX framework. World Meteorol Organ Bull 58:175-183. Available online at http:// wcrp.ipsl.jussieu.fr/RCD_Projects/CORDEX/CORDEX_giorgi_ WMO.pdf

Hernández-Díaz L, Laprise R, Sushama L, Martynov A, Winger K, Dugas B (2012) Climate simulation over the CORDEX-Africa domain using the fifth generation Canadian Regional Climate Model (CRCM5). Clim Dyn. doi:10.1007/s00382-012-1387-z Available online at http://www.springerlink.com/content/yl38x 21204070181/

Hourdin F, Guichard F, Favot F, Marquet P, Boone A, Lafore JP, Redelsperger JL, Ruti P, Dell'Aquila A, Doval TL, Traore AK, Gallee H (2010) AMMA-model intercomparison project. Bull Am Meteorol Soc 1:95-104

Huffman GJ, Adler RF, Morrissey MM, Bolvin DT, Curtis S, Joyce R, McGavock B, Susskind J (2001) Global precipitation at one-degree daily resolution from multisatellite observations. J Hydrometeorol 2:36-50

Huffman GJ, Adler RF, Bolvin DT, Gu G, Nelkin EJ, Bowman KP, Stocker EF, Wolff DB (2007) The TRMM multi-satellite precipitation analysis: quasi-global, multi-year, combined-sensor precipitation estimates at fine scale. J Hydrometeorol 8:33-55

IPCC AR4 (2007) Climate Change 2007: the physical science basis. In: Solomon S, Qin D, Manning M, Chen Z, Marquis M, Averyt $\mathrm{KB}$, Tignor M, Miller HL (eds) Contribution of Working Group I (WGI) to the fourth assessment report (AR4) of the Intergovernmental Panel on Climate Change (IPCC). Cambridge University Press, Cambridge. http://www.ipcc.ch/publications_ and_data/ar4/wg $1 /$ en/contents.html

Jones C, Giorgi F, Asrar G (2011) The coordinated regional downscaling experiment: CORDEX. an international downscaling link to CMIP5. CLIVAR Exch 56:34-40

Kain JS, Fritsch JM (1990) A one-dimensional entraining/detraining plume model and application in convective parameterization. J Atmos Sci 47:2784-2802

Koster RD, Sud YC, Guo Z, Dirmeyer PA, Bonan G, Oleson KW, Chan E, Verseghy D, Cox P, Davies H, Kowalczyk E, Gordon CT, Kanae S, Lawrence D, Liu P, Mocko D, Lu CH, Mitchell K, Malyshev S, McAvaney B, Oki T, Yamada T, Pitman A, Taylor CM, Vasic R, Xue Y (2006) The global land-atmosphere coupling experiment. Part I: overview. J Hydrometeorol 7:590-610

Kuo HL (1965) On formation and intensification of tropical cyclones through latent heat release by cumulus convection. J Atmos Sci 22:40-63

Lafore JP, Flamant C, Giraud V, Guichard F, Knippertz P, Mahfouf J-F, Mascart P, Williams ER (2010) Introduction to the AMMA special issue on advances in understanding atmospheric processes over West Africa through the AMMA field campaign. QJR Meteorol Soc 136:2-7. doi:10.1002/qj.583

Legates DR, Willmott CJ (1990a) Mean seasonal and spatial variability global surface air temperature. Theor Appl Climatol 41:11-21

Legates DR, Willmott CJ (1990b) Mean seasonal and spatial variability in gauge-corrected, global precipitation. Int J Climatol 10:111-127 
Li J, Barker HW (2005) A radiation algorithm with correlated-k distribution. Part I: local thermal equilibrium. J Atmos Sci 62:286-309

Martynov A, Sushama L, Laprise R (2010) Simulation of temperate freezing lakes by one-dimensional lake models: performance assessment for interactive coupling with regional climate models. Boreal Environ Res 15:143-164. ISSN 1797-2469 online; ISSN 1239-6095 print, 2010

Martynov A, Sushama L, Laprise R, Winger K, Dugas B (2012a) Interactive lakes in the Canadian Regional Climate Model, version 5: the role of lakes in the regional climate of North America. Tellus A 64:16226-16245. doi:10.3402/tellusa. v64i0.16226

Martynov A, Laprise R, Sushama L, Winger K, Šeparović L, Dugas B (2012b) Reanalysis-driven climate simulation over CORDEX North America domain using the Canadian Regional Climate Model, version 5: Model performance evaluation. Clim Dyn (in review)

Masson V, Champeaux J-L, Chauvin F, Meriguet Ch, Lacaze R (2003) A global database of land surface parameters at $1-\mathrm{km}$ resolution in meteorological and climate models. J Clim 16:1261-1282. Data available online at http://www.cnrm.meteo. fr/gmme/PROJETS/ECOCLIMAP/page_ecoclimap.htm

McFarlane NA (1987) The effect of orographically excited gravitywave drag on the general circulation of the lower stratosphere and troposphere. J Atmos Sci 44:1775-1800

Mitchell TD, Jones PD (2005) An improved method of constructing a database of monthly climate observations and associated highresolution grids. Int J Climatol 25:693-712

Mitchell TD, Carter TR, Jones PD, Hulme M, New M (2004) A comprehensive set of high-resolution grids of monthly climate for Europe and the globe: the observed record (1901-2000) and 16 scenarios (2001-2100). Tyndall Centre for Climate Change Research, Norwich, Working Paper 55. Available online at http://www.cru.uea.ac.uk/

Nikulin G, Jones C, Giorgi F, Asrar G, Büchner M, Cerezo-Mota R, Christensen $\mathrm{OB}$, Déqué $\mathrm{M}$, Fernandez J, Hänsler $\mathrm{A}$, van Meijgaard E, Samuelsson P, Sylla MB, Sushama L (2012) Precipitation climatology in an ensemble of CORDEX-Africa regional climate simulations. J Clim. doi:10.1175/JCLI-D11-00375.1

Paeth H, Hall Nicholas MJ, Gaertner MA, Dominguez Alonso M, Moumouni S, Polcher J, Ruti PM, Fink AH, Gosset M, Lebel T, Gaye AT, Rowell DP, Moufouma-Okia W, Jacob D, Rockel B, Giorgi F, Rummukainen M (2011) Progress in regional downscaling of West Africa precipitation. Atmos Sci Lett 12:75-82

Parker DJ, Burton RR, Diongue-Niang A, Ellis RJ, Felton M, Taylor CM, Thorncroft CD, Bessemoulin P, Tompkins AM (2005a) The diurnal cycle of the West African monsoon circulation. QJR Meteorol Soc 131:2839-2860

Parker DJ, Thorncroft CD, Burton RR, Diongue-Niang A (2005b) Analysis of the African easterly jet using aircraft observations from the JET2000 experiment. QJR Meteorol Soc 131:14611482. doi:10.1256/qj.03.189

Patricola CM, Cook KH (2010) Northern African climate at the end of the twenty-first century: an integrated application of regional and global climate models. Clim Dyn 35:193-212

Redelsperger JL, Thorncroft CD, Diedhiou A, Lebel T, Parker DJ, Polcher J (2006) African monsoon multidisciplinary analysis: an international research project and field campaign. Bull Am Meteorol Soc 87:1739-1746
Šeparović L, Alexandru A, Laprise R, Martynov A, Sushama L, Winger K, Tete K, Valin M (2012) Present climate and climate change over North America as simulated by the fifth-generation Canadian Regional Climate Model (CRCM5). Clim Dyn (in review)

Simmons AS, Uppala DD, Kobayashi S (2007) ERA-interim: new ECMWF reanalysis products from 1989 onwards. ECMWF Newslett 110:29-35

Sundqvist H, Berge E, Kristjansson JE (1989) Condensation and cloud parameterization studies with a mesoscale numerical weather prediction model. Mon Weather Rev 117:1641-1657

Sylla MB, Gaye AT, Jenkins GS, Pal JS, Giorgi F (2010) Consistency of projected drought over the Sahel with changes in the monsoon circulation and extremes in a regional climate model projections. J Geophys Res 115:D16108. doi:10.1029/2009JD012983

Taylor KE, Stouffer RJ, Meehl GA (2009) A summary of the CMIP5 experiment design. Available online at: http://cmip-pcmdi. 1lnl.gov/cmip5/docs/Taylor_CMIP5_design.pdf

Taylor KE, Stouffer RJ, Meehl GA (2012) An overview of CMIP5 and the experiment design. Bull Am Meteorol Soc 93:485-498. doi:10.1175/BAMS-D-11-00094.1

Thorncroft CD, Blackburn M (1999) Maintenance of the African easterly jet. QJR Meteorol Soc 125:763-786

Thorncroft CD, Nguyen H, Zhang C, Peyrillé P (2010) Annual cycle of the West African monsoon: regional circulations and associated water vapour transport. QJR Meteorol Soc 137:129-147. doi:10.1002/qj.728

Uppala S, Dee D, Kobayashi S, Berrisford P, Simmons A (2008) Towards a climate data assimilation system: status update of ERA-interim. ECMWF Newslett 115:12-18

van Vuuren DP, Edmonds J, Kainuma M, Riahi K, Thomson A, Hibbard K, Hurtt GC, Kram T, Krey V, Lamarque J-F, Masui T, Meinshausen M, Nakicenovic N, Smith SJ, Rose SK (2011) The representative concentration pathways: an overview. Clim Change 109:5-31. doi:10.1007/s10584-011-0148-z

Verseghy LD (2000) The Canadian land surface scheme (CLASS): its history and future. Atmos Ocean 38:1-13

Verseghy LD (2008) The Canadian land surface scheme: technical documentation-version 3.4. Climate Research Division, Science and Technology Branch, Environment Canada

Willmott CJ, Matsuura K, Legates DR (1998) Global air temperature and precipitation: regridded monthly and annual climatologies (version 2.01). Available online at http://climate.geog.udel. edu/ climate/

Xue Y, De Sales F, Lau WK-M, Boone A, Feng J, Dirmeyer P, Guo Z, Kim K-M, Kitoh A, Kumar V, Poccard-Leclercq I, Mahowald N, Moufouma-Okia W, Pegion P, Rowell DP, Schemm J, Schubert SD, Sealy A, Thiaw WM, Vintzileos A, Williams SF, Wu M-LC (2010) Intercomparison and analyses of the climatology of the West African monsoon in the West African monsoon modeling and evaluation project (WAMME) first model intercomparison experiment. Clim Dyn 35:3-27. doi: 10.1007/s00382-010-0778-2

Zadra A, Roch M, Laroche S, Charron M (2003) The subgrid-scale orographic blocking parameterization of the GEM model. Atmos Ocean 41:155-170

Zadra A, Caya D, Côté J, Dugas B, Jones C, Laprise R, Winger K, Caron LPh (2008) The next Canadian Regional Climate Model. Phys Canada 64:75-83 